\title{
HUELLAS DEL PODER: PIZARRAS Y POBLADOS CAMPESINOS EN EL CENTRO DE LA PENÍNSULA IBÉRICA (SIGLOS V-VII) ${ }^{1}$
}

\author{
IÑAKI MARTín VISO* \\ Universidad de Salamanca.
}

\begin{abstract}
Resumen
El objetivo del artículo es el análisis del significado social de las pizarras de época postromana (siglos V-VII). Para ello, se estudian los contextos arqueológicos en que las pizarras han aparecido en el centro de la península ibérica. El resultado es que hay una tendencia a su vinculación con espacios de poder, "lugares centrales" controlados por elites locales. Pero también aparecen pizarras en poblados rurales campesinos. A partir del estudio de cuatro casos bien documentados arqueológicamente, y haciendo especial hincapié en La Genestosa (Casillas de Flores, Salamanca), puede concluirse que estamos ante las marcas del poder de las elites sobre escenarios campesinos que no controlan directamente.
\end{abstract}

\section{Palabras clave}

Pizarras inscritas. Poblados. Elites. Campesinos. Época postromana.

\begin{abstract}
The aim of this paper is to analyze the social significance of post-Roman inscribed slates $\left(5^{\text {th }}-7^{\text {th }}\right.$ centuries). The study of the archaeological contexts of those slates uncovered in the central areas of the Iberian Peninsula has been carried out to better understand their function. As a result, we can see there is a clear tendency of linkage between the concentration of slates and those places controlled by local elites. However, some slates have also been uncovered in rural settlements inhabited by peasants. The analysis of four case studies -with particular emphasis on the site of La Genestosa (Casillas de Flores)- concluded that these slates must be considered as signs of power.
\end{abstract}

\section{Keywords}

Inscribed slates. Settlements. Elites. Peasants. post-Roman period.

\footnotetext{
Email: viso@usal.es

1 Este trabajo se ha realizado dentro del proyecto de investigación HAR2013-47889-C3-1-P, financiado por la Dirección General de Investigación del Ministerio de Economía y Competitividad. Agradezco a Jorge Díaz de la Torre, de la empresa Castellum, por los datos proporcionados acerca del yacimiento de Las Henrrenes. El trabajo se ha visto beneficiado por los comentarios y sugerencias de Rubén Rubio, Catarina Tente y Marina Vieira, a quienes quedo agradecido. De igual forma, se ha visto enriquecido por las interesantes sugerencias aportadas por los dos informantes anónimos, que han permitido matizar y mejorar el original.Todos los errores y omisiones son responsabilidad únicamente del autor.
} 


\begin{abstract}
Riassunto
Lo scopo di questo articolo è quello di analizzare il signficato sociale delle lastre di ardesia con iscrizioni di epoca post-romana (secoli V-VII). Sono presi in esame i contesti archeologici nei quali le iscrizioni sono apparse nell'area centrale della penisola iberica. Il risultato evidenzia il legame tra esse e gli spazi dell'esercizio del potere, i "luoghi centrali" controllati dalle elite locali. Si è però rilevato che esistono iscrizioni anche nei villaggi delle aree rurali. A partire dallo studio di quatto casi ben documentati archeologicamente, con particolare attenzione a "La Genestosa" (Casillas de Flores, Salamanca), si può concludere che tali attestazioni rimarcano i segni del potere e delle elite sulle aree rurali e sui gruppi di contadini che non erano controllati direttamente.
\end{abstract}

\title{
Parole chiave
}

Lastre di ardesia, insediamenti, elite, contadini, epoca post-romana.

\section{Arqueología de una escritura}

Las pizarras visigodas son un corpus de inscripciones realizadas sobre un soporte pétreo, la pizarra, cuyas dimensiones permiten su portabilidad, por lo que no son epígrafes monumentales. El conjunto de pizarras encierra por lo menos tres tipologías diferentes La primera está compuesta por las piezas con textos escritos en cursiva latina, cuyos contenidos son muy variados. Al menos se conocen 163 de estas piezas, aunque en muchas ocasiones solo se dispone de fragmentos muy reducidos de textos más amplios ${ }^{2}$. Estas pizarras son las más conocidas y estudiadas, al tratarse de documentos privados en un periodo en el que este tipo de informaciones escasean. La segunda la conforman las pizarras con inscripciones numéricas, definidas por la presencia de un conjunto de cifras escritas en el sistema latino. Son sin duda la tipología más frecuente, si bien en la mayoría de las ocasiones se trata de pequeños fragmentos de piezas mayores. Por último, están las inscripciones con dibujos, cuya interpretación presenta serias dificultades. La conclusión evidente es que el conjunto se define como un grupo de inscripciones que tienen en común el uso de un soporte específico, pero no por su contenido.

Las pizarras visigodas se han hallado fundamentalmente en el suroeste de la Meseta del Duero española (provincias de Salamanca y Ávila), así como en la vertiente meridional de las serranías que componen el Sistema Central, en el área cacereña ${ }^{3}$. Pero en los

\footnotetext{
2163 son recogidas en la edición más reciente de Isabel Velázquez Soriano, Las pizarras visigodas (Entre el latín y su disgregación), Instituto Castellano y Leonés de la Lengua, Burgos, 2004. El uso de la pizarra continuó en periodos posteriores, pero la función de tales textos es distinta y no deben integrarse en un solo conjunto. Así sucede con la pizarra encontrada en Fuente Encalada (Zamora) y publicada por Ángel Esparza Arroyo y Ricardo Martín Valls, "La pizarra altomedieval de Fuente Encalada (Zamora): contribución al estudio de las inscripciones profilácticas", Zephyrus, 51 (1998), pp. 237-262. También se conoce otra procedente de Huerga del Fraile (León), que debe datarse en un periodo posterior y que no ha sido publicada; Isabel Velázquez Soriano, Las pizarras visigodas..., pp. 39-40.

3 Isabel Velázquez Soriano, "La geografía de las pizarras: problemas planteados", En la pizarra. Los últimos hispanorromanos de la Meseta, Isabel Velázquez Soriano y Manuel Santonja Gómez (eds.), Instituto Castellano y Leonés de la Lengua, Burgos, 2005, pp. 93-109.
} 
últimos años se ha podido comprobar que el uso de la pizarra como material destinado a la escritura va más allá de ese foco principal, con hallazgos en otras zonas de la cuenca del Duero, en la actual región madrileña, en el entorno emeritense, en Braga, en el Baixo Alentejo portugués y en Andorra ${ }^{4}$.

Este variopinto corpus de inscripciones en pizarras encierra una serie de problemas en cuanto a su interpretación. En el caso de las piezas con textos, sus significados son muy variados: ejercicios escolares, gestión de la propiedad, pleitos, textos religiosos... Pero en muchas ocasiones tan sólo disponemos de un pequeño fragmento del texto original, por lo que resulta complicado averiguar qué nos están narrando. Mayores complicaciones ofrecen las pizarras numéricas. Cuando disponemos de piezas completas, se puede observar cómo recogen un sistema de contabilidad que parece haber sido común en el Mediterráneo Occidental ${ }^{5}$. Cada línea presenta una combinación distinta de números que suma una cantidad idéntica que se repite línea tras línea, aunque esa cifra varía según la pieza. Se trataría de un sistema de cuentas sencillo, que facilita la multiplicación de unidades homólogas. Sin duda estamos ante un sistema de contabilidad, pero ¿qué se está contando? ¿Quién cuenta y para qué? ${ }^{6}$ Son preguntas de difícil resolución, aunque podríamos ensayar respuestas parciales a partir de un estudio cuidadoso de los contextos arqueológicos en los que han aparecido.

\footnotetext{
4 Aránzazu Urbina Álvarez, "Pizarras con inscripción de época hispanovisigoda en la provincia de Madrid", La investigación arqueológica de la época visigoda en la Comunidad de Madrid. Zona Arqueológica, $n^{o}$ 8, Jorge Morín de Pablos (ed.), Museo Arqueológico Regional, Alcalá de Henares, 2006, vol. III, pp. 781-786. Ma Victoria CAlleja Martínez, "El poblamiento de época visigoda en el sureste de la provincia de Valladolid", V Congreso de Arqueología Medieval Española, Junta de Castilla y León, Valladolid, vol. 1, pp. 125-129; Fernando Regueras Grande y José Ignacio Martín Benito, "Hallazgos arqueológicos en el área de Benavente", Brigecio, 7 (1997), pp. 310-311; Luis Caballero Zoreda y Germana Megías PÉrez, "Informe de las excavaciones del poblado medieval del Cancho del Confesionario, Manzanares el Real (Madrid). Julio 1973”, Noticiario Arqueológico Hispánico, 5 (1977), pp. 325-331; Aránzazu Urbina Álvarez, "Hallazgo de dos pizarras con inscripción en el hábitat tardoantiguo del Cerro de la Virgen del Castillo (Bernardos, Segovia)", Faventia, 24/1 (2002), pp. 135-144; Tomas Cordero Ruiz e Iñaki MarTín VIso, "Sobre los usos y la cronología de las pizarras numerales: reflexiones a partir del caso del yacimiento de Valdelobos (Montijo, Badajoz)", Archivo Español de Arqueología, 85 (2012), pp. 253-266; Mário Jorge BARRoCA, "As pizarras visigodas. A propósito de uma obra de I. Velázquez Soriano", Conimbriga, 30 (1991), pp. 146-147; Catarina TENTE y António SoARes, "Uma pizarra visigoda com inscrição numérica em Santa Margarida (Serpa)", Arqueologia Medieval, 10 (2007), pp. 13-19; Isabel Velézquez Soriano, "Inscripció sobre pissarra", Roc d'Enclar. Transformaciones d'un espai dominant, segles IV-XIX, Govern d'Andorra, Andorra, 1997, pp. 418-422.

5 Las denominadas tablillas Albertini, documentos privados del Norte de África datados a finales del siglo $\mathrm{V}$, recogen una tablilla de cuentas con el mismo sistema matemático. Christian Courtors, Louis Leschi, Charles Perrat y Charles Saumagne. Tablettes Albertini. Actes privés de l'époque vandale (fin du Ve siècle), Arts et Métiers Graphiques, París, 1952.

6 Esta cuestión ya se la planteaba en su momento Isabel Velázquez Soriano, Las pizarras visigodas: edición crítica y estudio, Universidad de Murcia, Murcia, 1989, pp. 30-33 señalando que podrían ser o libros de contabilidad o ejercicios escolares, inclinándose por la primera opción. De todos modos, observaba que o bien no había una única explicación o se trataba de un sistema de contabilidad rústico y extendido por la zona.
} 
Sin embargo, muchos de los hallazgos se produjeron de manera fortuita o mediante intervenciones nada metódicas, efectuadas a finales del siglo XIX o comienzos del $\mathrm{XX}$, o simplemente fueron recogidas en superficie por vecinos y curiosos que las conservan en sus casas. Por otro lado, las características del material y su rápida amortización han permitido que las piezas hayan sido reaprovechadas como material constructivo7. Tal es el caso de Lancha del Trigo (Diego Álvaro, Ávila), donde las pizarras aparecieron formando parte del enlosado de las construcciones ${ }^{8}$. Debe añadirse que, gracias a su escaso peso y fácil portabilidad, han sido un material con frecuencia acarreado, aunque posiblemente no demasiado lejos de su lugar original, pues no se trata de grandes piezas y estamos ante un material relativamente abundante ${ }^{9}$. Por último, cuando se han detectado en intervenciones efectuadas con una metodología estratigráfica, el problema es que carecemos de excavaciones en extensión, pues o bien se han encontrado en espacios urbanos o bien no ha habido proyectos ambiciosos que hayan tratado de poner al descubierto un sitio al completo. No obstante, y a pesar de estas dificultades, algunos yacimientos nos han proporcionado un caudal de datos que nos permiten determinar los contextos arqueológicos en los que aparecen las pizarras ${ }^{10}$ (Fig. 1).

Un contexto muy frecuente es el compuesto por los sitios de altura o castella. Se trata de asentamientos fortificados, con murallas realizadas con materiales locales y sin la aplicación de complejas técnicas poliorcéticas. Se emplazan en lugares de relevancia comarcal, controlando pasos fluviales o rutas ganaderas. Sin duda este conjunto de lugares responde a una gran diversidad de orígenes, funciones y tipologías. Recientemente, se ha planteado la diferenciación entre los castella que surgen en áreas donde se colapsan las antiguas ciuitates, entre los que aparecen en zonas donde sobreviven las ciuitates, pero situándose en ámbitos periféricos con respecto a los antiguos territorios urbanos, $\mathrm{y}$ los que emergen en áreas hasta entonces escasamente urbanizadas. En todos los casos, la explicación estaría en el surgimiento de poderes locales que entablaron una relación ambivalente con el poder central a partir de finales del siglo VI ${ }^{11}$. En la zona de mayor presencia de las pizarras, los castella se identifican con la segunda de las tipologías, conviviendo con las ciudades y emplazados en puntos de la periferia del territorio de

\footnotetext{
Una realidad que ya señalaba en su momento Manuel C. DíAz y DíAz, "Los documentos hispano-visigóticos sobre pizarra", Studi Medievali, VII-1(1966), p. 76.

8 Arsenio Gutiérrez Palacios, Manuel C. Díaz y Díaz y Juan Maluquer de Motes, "Excavaciones en la Lancha del Trigo, Diego Álvaro (Ávila)", Zephyrus, IX (1958), pp. 59-78.

9 Ese debe ser el caso de los tres fragmentos de pizarra numérica encontrados en el pago de Peña Perdiguera, en Martínez (Ávila). Ma del Mar Gabaldón Martínez y Ma Teresa Jiménez Pardo, "Tres nuevas pizarras visigodas con signos numéricos procedentes de Martínez, Ávila", II Congreso de Arqueología Peninsular, Fundación Rei Afonso Henriques, Zamora, 1999, vol. IV, pp. 451-455.

10 Sobre estos contextos, explicados con mayor detalle, véase Iñaki Martín VISo, "The Visigothic slates and their archaeological contexts", Journal of Medieval Iberian Studies, 5:2 (2013), pp. 145-168.

11 Juan Antonio Quirós Castillo, "Defensive sites of the Early Middle Ages in North-West Spain", Landscapes of Defence in Early Medieval Europe, John Baker, Stuart Brookes y Andrew Reynolds (eds.), Brepols, Turnhout, 2013, pp. 312-313.
} 


\section{FIGURA 1}

Lugares del centro peninsular citados en el texto: 1 . Ávila; 2. Coca; 3. Cuarto de Enmedio; 4. Dehesa del Aguasal; 5. Dehesa del Castillo; 6. El Cancho del Confesionario; 7. El Cortinal de San Juan; 8. El Pelícano; 9. La Cabeza de Navasangil; 10. La Cárcava de la Peladera; 11. La Genestosa; 12. La Legoriza; 13. La Llosa; 14. Las Henrrenes; 15. Lerilla; 16. Los Nuevos; 17. Monte el Alcaide; 18. San Pelayo; 19. Virgen del Castillo.

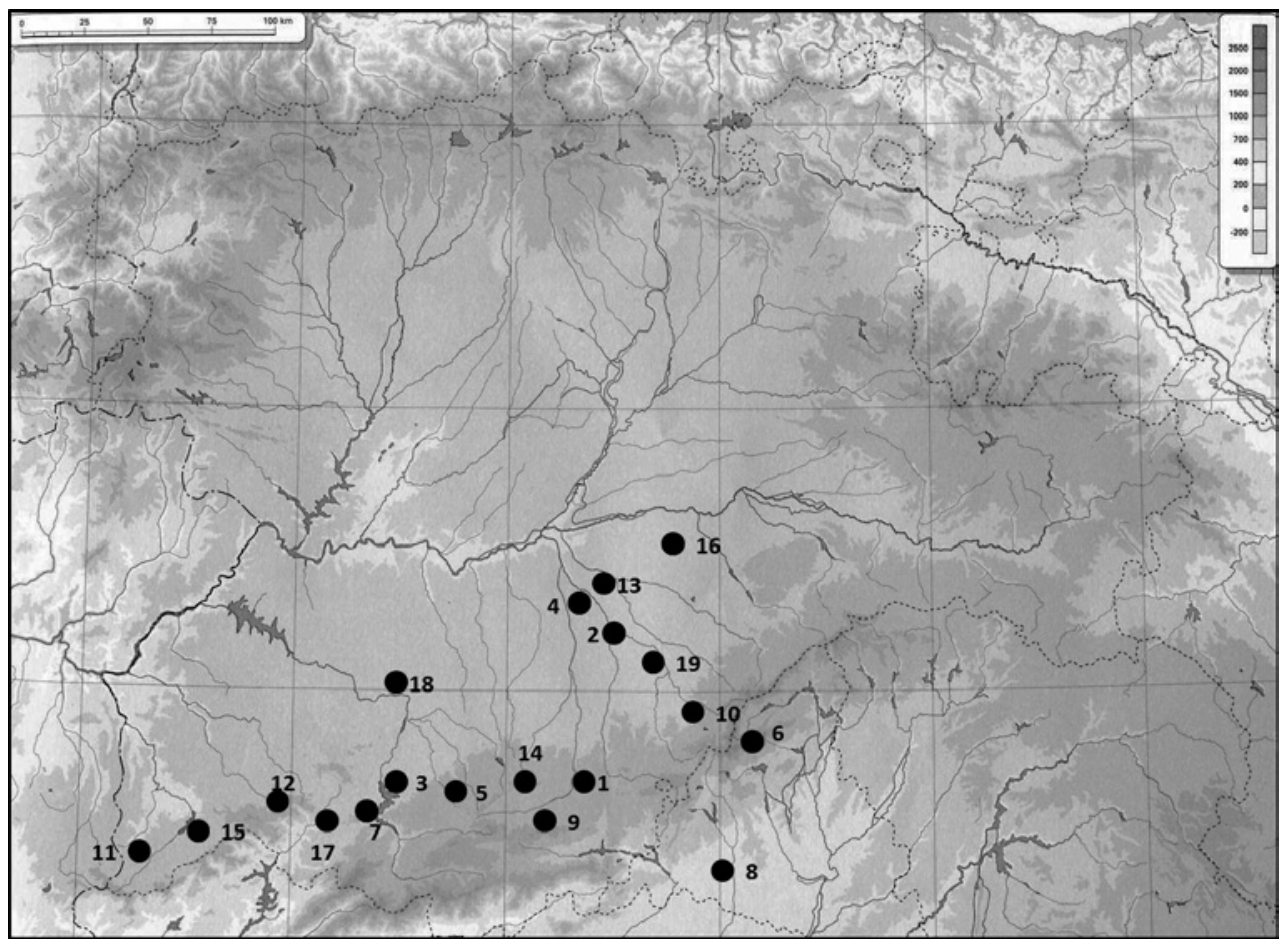

las ciuitates $^{12}$. Serían la plasmación de nuevas elites, que dominaron espacios rurales de ámbito comarcal, a partir del siglo V, para posteriormente integrarse en el sistema político visigodo, pero manteniendo un cierto margen de autonomía ${ }^{13}$. Sin embargo, no se han llevado excavaciones sistemáticas, por lo que existen dudas acerca de esta

\footnotetext{
12 Iñaki MARTín Viso, "Castella y elites en el suroeste de la meseta del Duero postromana", Las fortificaciones en la tardoantigüedad. Elites y articulación del territorio (siglos V-VIII d.C.), Raúl Catalán, Patricia Fuentes y José Carlos Sastre (eds.), La Ergástula, Madrid, 2014, pp. 247-274.

13 Sobre el carácter de estos castella como elementos asociados a las elites, Alexandra Chavarría Arnau, "Dopo la fine delle ville: le champagne ispaniche in época visigota (VI-VII secolo), Dopo la fine delle ville: le campagne dal VI al IX secolo, Gian Pietro Brogiolo (ed.), Società Archeologica Padana, Mantua, 2005, pp. 263-285. Para la zona de estudio, véase Iñaki MARTín VISO, "La ordenación del territorio rural y la tributación en el suroeste de la meseta del Duero (siglos VI-VII)", De Roma a los bárbaros. Poder central $y$ horizontes locales en la cuenca del Duero, Santiago Castellanos e Iñaki Martín Viso (eds.), Universidad de León, León, pp. 227-261.
} 
hipótesis ${ }^{14}$, e incluso se maneja la idea de una creación estatal al calor de la frontera suevo-visigoda al menos en este ámbito regional ${ }^{15}$. Sin embargo, la ausencia de un formato constructivo regularizado, las dimensiones de los asentamientos, que van más allá de una guarnición, el tipo de hallazgos, propio de una comunidad no necesariamente militar, así como la difícil interpretación de la localización de estos lugares en términos geoestratégicos, parecen ser elementos que no encajan con una iniciativa estatal, que tendería a estandarizar las técnicas poliorcéticas. Por el contrario, las características formales se ajustarían mejor a la hipótesis de una iniciativa de poderes locales, de los cuales hay información al menos para los siglos V-VI en la meseta del Duero ${ }^{16}$.

En algunos de estos castella, se han encontrado numerosas pizarras. Así sucede en Lerilla (Zamarra, Salamanca), de donde se conservan más de 900 fragmentos (Fig. 2). Pero este lugar no ha sido objeto de una intervención arqueológica y hay dudas con respecto a origen de las piezas, que podían proceder de otros lugares ${ }^{17}$. Por tanto, no puede servirnos como modelo de análisis, a pesar de que las pizarras numerales suelen denominarse también de tipo Lerilla. Un lugar que proporciona evidencias más seguras es El Cortinal de San Juan (Salvatierra de Tormes, Salamanca), de donde proceden más de un centenar de pizarras. Aunque la mayoría de ellas proceden de colecciones privadas compuestas por hallazgos en superficie no controlados, se llevó a cabo una alguna pequeña campaña de excavación que permitió recuperar alguna pieza, y que además dató el lugar a través de la presencia de cerámicas estampilladas, a lo que se

\footnotetext{
14 Enrique ARIÑo, "El hábitat rural en la península ibérica entre finales del siglo IV y principios del VIII: un ensayo interpretativo", Antiquité Tardive, 21 (2013), pp. 110-116.

15 Enrique Ariño Gil y Pablo de la Cruz Díaz, "La frontera suevo-visigoda. Ensayo de lectura de un territorio en disputa", Las fortificaciones en la tardoantigüedad. Elites y articulación del territorio (siglos V-VIII d.C.), Raúl Catalán, Patricia Fuentes y José Carlos Sastre (eds.), La Ergástula, Madrid, 2014, pp. 179-190.

16 Los datos del interesante estudio citado en la nota anterior pueden ser leídos de otra forma, pues podrían reflejar que en las zonas donde la intensidad del dominio político central fue menor, la relevancia de las elites locales y de los castella se incrementó. Al fin y al cabo, entre mediados del siglo $\mathrm{V}$ y el reinado de Leovigildo (569-585) no hay evidencias de que esta zona fuese un área en conflicto. En cualquier caso, se observa cómo puede llegarse a conclusiones muy dispares (y factibles) a partir de un registro que es escaso y problemático. Sobre los poderes locales en la meseta del Duero, véase Santiago Castellanos, "La construcción del poder político visigodo y los horizontes locales: canales de participación y de hostilidad", De Roma a los bárbaros. Poder central y horizontes locales en la cuenca del Duero, Santiago Castellanos e Iñaki Martín Viso (eds.), Universidad de León, León, pp. 145-170.

17 Isabel Velázquez Soriano, Documentos de época visigoda escritos en pizarra (siglos VI-VIII), Brepols, Turnhout, 2000, vol. II, p. 6. Esas pizarras proceden de la colección privada del canónigo Serafín Tella, que las recogió durante el primer tercio del siglo XX. Han sido catalogadas por Jorge Morín de Pablos, aunque no he podido consultar su tesis doctoral inédita La época visigoda en el Occidente de la Meseta Norte. Provincias de León, Zamora y Salamanca (siglos V al VIII d.C.), Madrid, 2003. Por otro lado, he tenido acceso a las mismas, que se guardan en el Archivo Catedralicio de Ciudad Rodrigo y algunas de ellas están expuestas en el Museo Catedralicio. Aunque la duda sobre el origen parece razonable, de momento no hay evidencias inequívocas de que esas pizarras procedan de otros lugares, sino más bien sospechas. A ello se añade que el alto número de fragmentos no debe llamarnos tanto la atención, porque en su mayoría son de muy pequeñas dimensiones, por lo que el número de piezas originales pudo haber sido mucho menor.
} 


\section{FigURA 2}

\section{El castellum de Lerilla (Zamarra, Salamanca).}

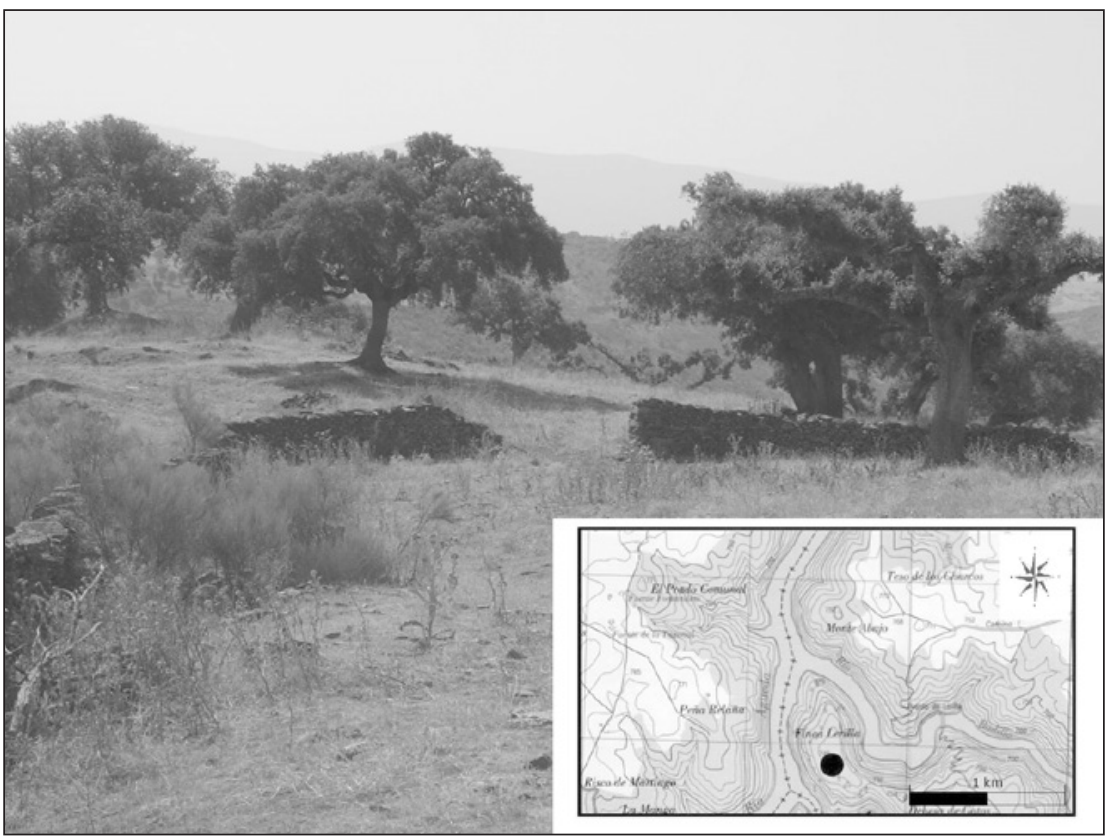

une la existencia de restos escultóricos referidos a un edificio eclesiástico ${ }^{18}$. Estas piezas proceden todas ellas del mismo lugar, El Cortinal de San Juan, un pequeño espacio situado junto al castillo del lugar, aunque en la parte externa a las murallas de la villa, y cerca del cantil del pantano actual. También en La Cabeza de Navasangil (Solosancho, Ávila), un lugar situado sobre el Valle Amblés, se recuperaron cerca de una treintena de pizarras. En la última intervención realizada en este lugar, se encontró una pizarra junto con una tinaja de almacenaje con cereal carbonizado y puntas de lanzas en una estructura junto a la muralla ${ }^{19}$. Al sur del Sistema Central nos encontramos con El Cancho del Confesionario (Manzanares el Real, Madrid), un asentamiento con características muy similares a los castella descritos y donde se habrían recuperado algunas pizarras

18 Enrique CERrillo, "Informe sobre las excavaciones realizadas en el yacimiento de "El Cortinal de San Juan", Salvatierra de Tormes (Salamanca), 1973”, Noticiario Arqueológico Hispano, 5 (1977), pp. 313-318; Pablo de la Cruz DíAz e Iñaki Martín Viso "Una contabilidad esquiva: las pizarras numerales visigodas y el caso de El Cortinal de San Juan (Salvatierra de Tormes, España)", Between taxation and rent. Fiscal problems from Late Antiquity to Early Middle Ages, Pablo de la Cruz Díaz e Iñaki Martín Viso (eds.), Edipuglia, Bari, 2011, pp. 221-250; Enrique AriÑo, "El yacimiento de El Cortinal de San Juan (Salvatierra de Tormes, Salamanca) y su contexto arqueológico", ibidem, pp. 251-270.

19 Jesús Caballero Arribas y David Peñas Pedrero, "Un castrum de época visigoda en el Valle Amblés: La Cabeza de Navasangil (Solosancho, Ávila)", Los castillos altomedievales en el Noroeste de la península ibérica, Juan Antonio Quirós Castillo y José Ma Tejado Sebastián (eds.), Universidad del País Vasco, Bilbao, 2012, pp. 213-238. 
en los años 70 del siglo pasado, aunque la información es muy escasa ${ }^{20}$. También se encontraron dos pizarras numéricas en Virgen del Castillo (Bernardos, Segovia), una en un nivel de revuelto consecuencia de los zanjeos realizados en el paramento interior de la muralla y otra amortizada como material constructivo en un contexto procedente de la última fase de ocupación ${ }^{21}$.

Los hallazgos en estos castella se caracterizan por dos rasgos. En primer lugar, son los lugares donde se encuentran las mayores concentraciones de pizarras, como sucede quizá en Lerilla y sobre todo en El Cortinal de San Juan. En segundo lugar, las piezas corresponden de una manera abrumadora a la tipología de pizarras numéricas. Únicamente se han recuperado algunas piezas con textos escritos en Lerilla -con los problemas que plantea el origen de las pizarras teóricamente procedentes de ese lugar- y El Cortinal de San Juan, pero corresponden a listados de individuos, a veces seguidos por un numeral $^{22}$. Podría entenderse como un modelo similar a la información de las pizarras, pero aquí se incluiría el nombre de la persona vinculada a la cantidad correspondiente. Por otro lado, han aparecido en los últimos años pizarras en contextos urbanos. Así sucede en Ávila (Abela), donde algunas recientes excavaciones de urgencia han revelado la existencia de pizarras en el casco urbano (Fig. 3). Es el caso del Episcopio, dentro del recinto amurallado de la ciudad, donde aparecieron cerámicas estampilladas y dos pizarras numéricas, así como un tremís de oro de Chindasvinto (642-649) en una unidad estratigráfica prácticamente coetánea ${ }^{23}$. En el palacio de Gaspar del Águila o antiguo convento de Los Paúles, dentro igualmente del recinto fortificado, también se ha detectado la existencia de pizarras ${ }^{24}$. Otro ejemplo es Coca (Cauca), un núcleo documentado en el periodo postromano como municipium y que quizá deba entenderse como un centro urbano al menos en el periodo tardorromano ${ }^{25}$. En el área conocida como Los Azafranales, junto al posible núcleo tardorromano, se ha encontrado medio centenar de pizarras numéricas, buena parte de las cuales estaban depositadas en un

\footnotetext{
20 Luis Caballero Zoreda y Germana Megías Pérez, "Informe de las excavaciones...".

21 Aránzazu Urbina Álvarez, "Hallazgo de dos pizarras..."; José Ma Gonzalo Gonzalo, El Cerro del Castillo, Bernardos (Segovia). Un yacimiento singular en la provincia de Segovia durante la Antigüedad Tardia, Caja Segovia, Segovia, 2006, p. 91.

22 Isabel Velázquez Soriano, Las pizarras visigodas..., números 1, 6, 117, 118, 119 y 120. Cabría añadir la pizarra $\mathrm{n}^{\circ} 7$, cuyo contenido parece ajustarse a una especie de ejercicio escolar, copiando en cada línea textos que no se ligan con los de las líneas anterior o posterior. Por tanto, puede aceptarse que los únicos documentos extraídos son precisamente esos listados de nombres, ya que no estaríamos ante un documento en sí mismo, sino más bien un ejercicio.

23 Jorge Díaz de LA ToRre, Informe final $\left(1^{a} y 2^{a}\right.$ fase) de los trabajos arqueológicos efectuados en el entorno del Episcopio (Ávila de los Caballeros) Castellum S. Coop, Ávila, 2003 [Informe arqueológico inédito].

24 Soledad Estremela Portela, "La excavación arqueológica: una mirada a la historia de Ávila", Arqueología urbana en Ávila. La intervención en los solares del Palacio de don Gaspar del Águila y Bracamonte (antiguo convento de los Padres Paúles), Soledad Estremela Portela (ed.), Junta de Castilla y León, Valladolid, 2006, p. 59; Inés Centeno Cea, "La ciudad entre los siglos IV y VII. El mundo tardoantiguo", ibídem, pp.128-129. 25 Gonzalo Martínez Díez y Félix Rodríguez (eds.), La colección canónica hispana. Vol. IV, CSIC, Madrid, 1984, p. 365.
} 
basurero y en una zanja ${ }^{26}$. Por otro lado, en el pago denominado Tierra de las Pizarras o Las Pizarras, a unos 2000 metros al norte del actual casco urbano, se ha excavado una villa, posteriormente amortizada por un espacio de enterramiento postromano, donde apareció una pizarra, fragmentada en seis trozos, como consecuencia de una actividad de unos furtivos en el año $2001^{27}$. En definitiva, disponemos de claras evidencias de la presencia de pizarras numéricas - pero no de texto-en ámbitos urbanos.

FIGURA 3

Localización de los hallazgos de pizarras numéricas en la ciudad de Ávila.

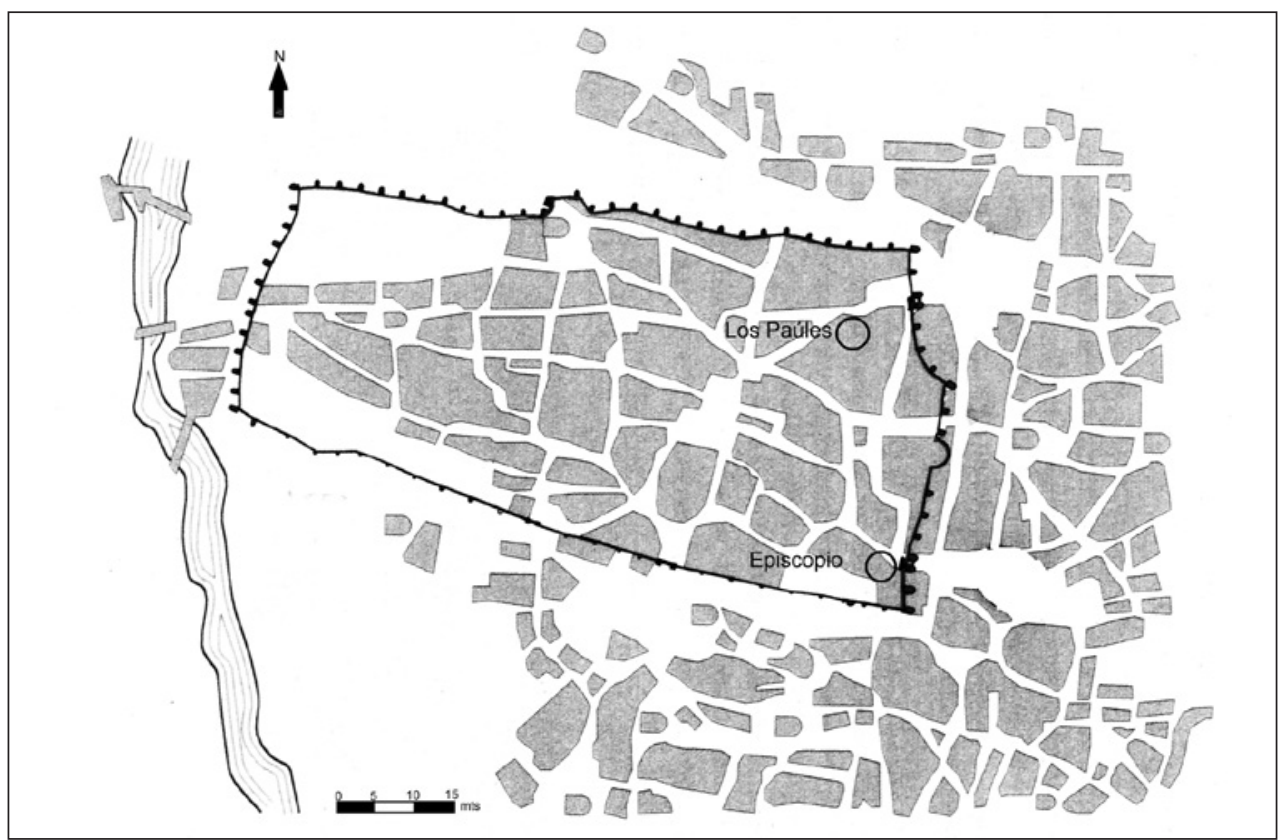

Junto a castella y ciuitates, destaca la existencia de pizarras numéricas procedentes de lugares rurales vinculados a la presencia de importantes actividades productivas, que quizá fueran asentamientos campesinos. Tal es el caso de Monte el Alcaide (Monleón, Salamanca), que se ha interpretado como un espacio destinado a la producción vinícola. Aquí se recuperaron once pizarras con algunos fragmentos de escritura y ocho

26 Carlos Sáez Sánchez, "Hallazgo de pizarras visigodas cifradas en Coca de la Vega", Anuario de Estudios Medievales, 15 (1985), pp. 35-37; Juan Francisco Blanco García, "Aproximación a la Cauca del Bajo Imperio", Congreso internacional la Hispania de Teodosio, Junta de Castilla y León, Salamanca, 1997, vol. II, pp. 377-393. Salamanca: Junta de Castilla y León, 1998; Juan Francisco Blanco García, "Coca, Cauca," Arqueología del área central de la cuenca del rio Duero: de Simancas a Coca, Tomás Mañanes (ed.), Diputación de Valladolid, Valladolid, 2002, p. 169; Cesáreo Pérez GonZÁlez y Olivia Reyes Hernando, "Epigrafía caucense (II)", Oppidum. Cuadernos de Investigación, 5 (2009), pp. 50-54.

27 Cesáreo Pérez González y Olivia Reyes Hernando, “Epigrafía caucense...”, pp.54-56. 
numéricas. Un aspecto reseñable es que tres de estas pizarras numéricas se encontraron asociadas a una estancia en la cual había una pileta tallada en un bloque de granito, con una capacidad de unos 28 litros. Esas tres pizarras estaban colocadas horizontalmente dispuestas con intencionalidad sobre el pavimento, por lo que resulta factible que estuvieran vinculadas con lo que se estaba contando en la pila ${ }^{28}$. Por otra parte, en La Legoriza (San Martín del Castañar, Salamanca), se han exhumado una serie de estructuras que parecen asociarse a la presencia de actividades metalúrgicas. En este yacimiento, se han encontrado varias pizarras numéricas, así como algunas de dibujo y otras de texto. Los hallazgos se distribuyen por distintas estructuras situadas en el entorno supuestamente metalúrgico. Todos estos datos parecen señalar que las pizarras se vincularían fundamentalmente con un espacio de carácter productivo ${ }^{29}$. Es posible que la concentración de estos lugares en el área serrana pueda responder a una situación comarcal muy específica, con un auge de la producción oleícola y metalúrgica, que habría permitido la formación de poblados asociados a esa producción, si bien de momento no está claro que podamos hablar de asentamientos campesinos. En todo caso, la existencia de una intensa actividad productiva explicaría la presencia de pizarras.

Pero el lugar más conocido de entre los que proporcionan pizarras es Dehesa del Castillo (Diego Álvaro, Ávila) y corresponde a otro tipo de contexto. Se trata de un pago situado a un kilómetro al sur de la localidad actual, en torno a una colina (Fig. 4). Es precisamente en ese sector donde se encontraron las pizarras. De este lugar proceden 31 pizarras con textos, a las que deben añadirse diez que posiblemente provengan de ese mismo sitio y otras diecisiete halladas en el cercano yacimiento de Lancha del Trigo, de las que se acepta que son un material reaprovechado recogido en Dehesa del Castillo $^{30}$. Pero además se recogieron algunas pizarras numéricas, que se conservan en el Museo de Ávila ${ }^{31}$. Desgraciadamente la información sobre los datos de la excavación de los años 40 del siglo pasado es parca ${ }^{32}$. Un aspecto importante es que el contenido

28 Fernando Paricio Alonso y María Vinuesa Chao, "Monte el Alcaide: un yacimiento altomedieval en el alto valle del Alagón (Monleón, Salamanca)", ¿Tiempos oscuros? Territorio y sociedad en el centro de la península ibérica (siglos VII-X), Iñaki Martín Viso (ed.), Sílex, Madrid, 2009, pp. 58-59.

29 José Antonio Gómez Gandullo, "Avance de las excavaciones arqueológicas en el yacimiento de época visigoda de La Legoriza, San Martín del Castañar (Salamanca)", La investigación arqueológica de la época visigoda en la comunidad de Madrid. Zona Arqueológica, $n^{\circ}$ 8, Jorge Morín de Pablos (Ed.), Museo Arqueológico Regional, Alcalá de Henares, 2006, vol. I, pp. 217-235. También se han consultado los informes relativos a las campañas efectuadas en este lugar entre 2004 y 2008 y depositados en el Museo de Salamanca.

30 Arsenio Gutiérrez Palacios, Manuel C. Díaz y Díaz y Juan Maluquer de Motes, "Excavaciones en la Lancha del Trigo...". Los datos proceden de Isabel VelázQuez Soriano, Las pizarras visigodas...

31 Arsenio Gutiérrez Palacios, "Dibujos de materiales y pizarras escritas de Diego Álvaro (Ávila)", Crónica del IV Congreso Arqueológico del Sudeste Español, Junta Municipal de Arqueología y Museo de Cartagena, Cartagena, 1949, p. 528; Arsenio Gutiérrez Palacios, Miscelánea arqueológica de Diego Álvaro, Institución Gran Duque de Alba, Ávila, 1966, p. 82.

32 Se ha revisado toda la documentación sobre la excavación de los años 40 conservada en los fondos del Museo de Ávila. Las publicaciones acerca de este sitio son escasas y poco clarificadoras. Véanse Arsenio Gutiérrez Palacios, “Crónica de arqueología abulense”, Zephyrus, VII (1956), pp. 92-94; Arsenio Gutiérrez Palacios, Miscelánea arqueológica..., pp. 81-83. Puede verse una presentación del yacimiento en Isabel 
de las pizarras con textos es muy variado (compraventas, documentos relacionados con pleitos, pagos, un documento de hospitium...) e incluso un par de textos de posible carácter religioso. Esta diversidad podría corresponder a un archivo en el cual se estaría depositando toda aquella documentación que se juzgaba relevante. La incorporación de textos religiosos hace sospechar que estaríamos ante un centro eclesiástico. Esto no significa que fuese un archivo específico de una institución religiosa sino que ésta podría servir de receptora y guardiana de esos textos, que podrían afectar a personas cercanas, pero no necesariamente a la institución, depositadas allí por mayor seguridad o quizá por vínculos familiares ${ }^{33}$. Estaríamos ante un "archivo en piedra".

\section{FIGURA 4}

\section{Dehesa del Castillo (Diego Álvaro, Ávila).}

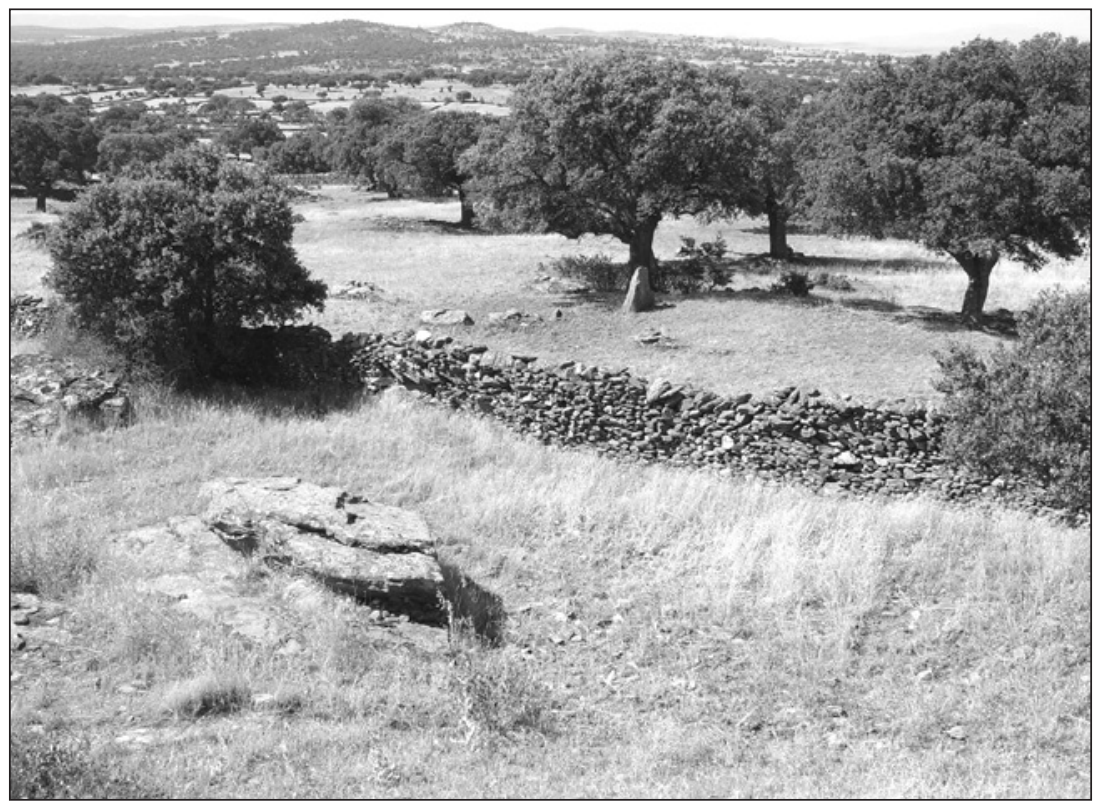

Resulta interesante comparar Dehesa del Castillo con yacimientos que presentan características semejantes, como Cuarto de Enmedio (Pelayos, Salamanca). El corpus de pizarras procedentes de ese lugar está compuesto por catorce piezas con texto, la mayor parte de ellas pequeños fragmentos de otras mayores, cuyos contenidos parecen

\footnotetext{
Velázquez Soriano, Documentos de época visigoda..., 17-18 y en Iñaki Martín Viso, "La ordenación....", p. 238.

33 Puede compararse con los casos de los archivos hallados en contextos religiosos de la Palestina bizantina. Casper J. Kraemer, Excavations at Nessana. Volume 3. Non-literary papyri. Princeton: Princeton University Press, Princeton, 1958, pp. 4-8 y Jaako Frösén, Anti ArJaVA y Marjo Lehtinen, The Petra papyri, I, American Center of Oriental Research, Amman, 2002, pp. 5-10.
} 
ser muy heterogéneos: listados de individuos, posibles pagos y significativamente un texto religioso ${ }^{34}$. Se encontraron en un área objeto de una intervención en los años 90 , cuando se exhumó un edificio basilical de tres naves ${ }^{35}$. Puede pensarse en una iglesia o monasterio, de donde procederían las pizarras, conservadas en muy mal estado debido al movimiento de las aguas del embalse de Santa Teresa, pues el lugar se halla en la zona de inundación de dicho pantano. Por tanto, una hipótesis es que buena parte de las pizarras de texto correspondan a antiguos archivos vinculados a iglesias y/o monasterios locales de época postromana, que conservaban una documentación muy variopinta, usados como depósitos de una información relevante para los habitantes de los alrededores, aunque la documentación podía ser propia de laicos ${ }^{36}$.

Hay además otros contextos en los que han aparecido pizarras. Tal es el caso de algunas uillae, como sucede con el ya citado caso de Tierra de las Pizarras, pero también en San Pelayo (Aldealengua, Salamanca) $)^{37}$ y en Valdelobos (Montijo, Badajoz) ${ }^{38}$. En todos los casos, se trata de unos pocos ejemplares de pizarras numéricas (una pieza, a lo sumo fragmentada) y se vincula a fases de abandono, como sucede en San Pelayo donde la pizarra aparece en un basurero, o de reorganización, como en Tierra de las Pizarras y sobre todo a Valdelobos, donde la pizarra apareció en la necrópolis postromana, posiblemente como material reaprovechado. Lo interesante del dato es que parece retrotraer el uso de las pizarras como material de escritura asociado a la contabilidad al periodo tardorromano, pues los usos de tales piezas no pueden asociarse en ninguno de los casos señalados a fases posteriores, donde se detecta el abandono de las uillae o su amortización por espacios funerarios.

Este somero recorrido permite advertir de la pluralidad de situaciones en las que nos encontramos con hallazgos de pizarras ${ }^{39}$. Conviene, de todos modos, destacar la particularidad de los contextos de pizarras con textos escritos, sobre todo cuando encontramos grandes cantidades, ya que responden a posibles patrones asociados a centros eclesiásticos. Por otro lado, los hallazgos de pizarras numéricas corresponden a un patrón

\footnotetext{
34 Isabel Velázquez Soriano, Las pizarras visigodas..., números 22, 23, 24, 127, 128, 129, 130, 131, 132, $133,134,156,157$ y 158.

35 Isabel Velázquez Soriano, "Pizarras visigodas: nuevos datos y comentarios", De la Antigüedad al Medievo. Siglos IV-VIII, Fundación Sánchez-Albornoz, Ávila, 1993, pp. 432-434; José Jacobo StorCh DE GraCia Y AsENSIO, "Avance de las primeras actividades arqueológicas en lo hispano-visigodos de la Dehesa del Cañal (Pelayos, Salamanca)", Arqueología, Paleontología y Etnografia, 4 (1998) (Ejemplar monográfico dedicado a Jornadas Internacionales Los visigodos y su mundo), pp. 151-154.

36 Sobre la documentación laica en este periodo, entre la cual estarían las pizarras, veáse Nicholas EvERETT, "Lay documents and archives in early medieval Spain and Italia, c.400-700", Documentary culture and the laity in the Early Middle Ages, Warren Brown, Marios Costambeys, Mathew Innes y Adam Kosto (eds.), Cambridge University Press, Cambridge, 2012, pp. 63-94.

37 Sarah Dahi Elena, "Un contexto cerámico de la Antigüedad tardía: el yacimiento de San Pelayo (Aldealengua, Salamanca). Nuevos datos sobre la cronología de las pizarras visigodas", Pyrenae, 38-1 (2007), pp. 79-104.

38 Tomas Cordero Ruiz e Iñaki Martín Viso, "Sobre los usos y la cronología...".

39 Una diversidad que ya fue puesta de manifiesto por Isabel Velázquez Soriano, Las pizarras visigodas: edición crítica..., pp. 31-33.
} 
diferenciado de los "archivos en piedra", con independencia de que puedan aparecer algunos textos, casi siempre listados de individuos ${ }^{40}$. Un dato interesante es que desde el punto de vista cronológico las primeras pizarras numéricas se vinculan a contextos dominicales, asociadas probablemente a la gestión doméstica de determinadas uillae. Ahora bien, la concentración de hallazgos implica la existencia de oficinas que precisaban de una contabilidad constante. Llama la atención el hecho de que las pizarras numéricas se encuentran en posiciones secundarias, incluso en basureros, muestra de que eran documentos para un registro inmediato de algo que se estaba viendo directamente y que no era necesario apuntar, pero no se archivaban. Dadas sus características internas, es muy posible que sirvieran para confeccionar otros documentos más precisos, semejantes a los listados de antropónimos u otros que no se han conservado.

La presencia de un alto número de pizarras numéricas en contextos productivos podría explicarse como una muestra de la gestión de esos lugares, quizá en relación con un control externo de esa actividad. Pero es especialmente llamativa la presencia de oficinas contables en determinados castella, que difícilmente pueden estar vinculados con una gestión de carácter dominical. Algunas investigaciones recientes han advertido de la posible relación con aspectos tributarios ${ }^{41}$. Esta línea de trabajo ha servido para caracterizar las pizarras procedentes de El Cortinal de San Juan como una huella de un posible peaje fluvial, a tenor de algunas representaciones gráficas de barcos y de

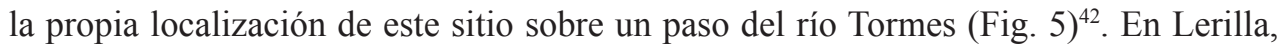
algunas pizarras presentan imágenes de animales (Fig. 6), por lo que quizá el objeto del gravamen fuese el ganado ${ }^{43}$. Una hipótesis que puede relacionarse con otros datos, como los proporcionados por una pizarra procedente de Santibáñez de la Sierra (Salamanca). Dicha pieza conserva en su parte superior una serie de anotaciones numerales, con líneas que suman 26 unidades, y en su parte inferior un breve texto que parece indicar un peaje sobre el ganado bovino ${ }^{44}$. Por último, en La Cabeza de Navasangil se ha planteado la hipótesis de un gravamen cerealístico, ya que la pizarra apareció junto a abundante grano ${ }^{45}$.

\footnotetext{
40 Iñaki MARTín VISO, “The Visigothic slates...”.Una opinión contraria, que considera que la diferenciación entre lugares con pizarras escritas y sitios con pizarras numéricas no es operativa, es la de Isabel VeLÁzQueZ Soriano, Documentos..., vol. II, p. 6, que corrige así su postura de la edición de 1989 (Las pizarras visigodas: edición crítica..., p. 29). De todos modos, el análisis que se presenta sí parece identificar algunas diferencias, que no son necesariamente oposiciones, pues es común que ambas tipologías aparezcan en un mismo lugar. La cantidad de piezas de cada tipo y los contenidos de los textos parecen ser evidencias de diferencias entre unos y otros lugares. En ese sentido, creo que hay una diferencia entre los lugares con abundantes pizarras de texto y los que concentran básicamente pizarras numéricas.

41 Iñaki MARTín Viso, "Tributación y escenarios locales en el centro de la Península Ibérica: algunas hipótesis a partir del análisis de las pizarras visigodas", Antiquité Tardive, 14 (2006), pp. 272-273.

42 Pablo de la Cruz Díaz e Iñaki Martín VIso "Una contabilidad esquiva....", p. 242.

43 Juan CABré Aguiló, "El castro de Lerilla y sus placas de pizarra con inscripciones y grabados", Actas y Memorias de la Sociedad Española de Antropología, Etnología y Prehistoria, IX (1930), pp. 163-174 identificó los animales con lobos y en un caso con una cierva. Podría tratarse de escenas de caza, pero, una vez revisadas las pizarras, son posibles otras identificaciones.

44 Isabel Velázquez Soriano, Las pizarras visigodas..., número 2.

45 Jesús Caballero Arribas y David Peñas Pedrero, "Un castrum de época visigoda...", pp. 225-226.
} 


\section{FigURA 5}

Pizarra numérica con representación de un barco, procedente de El Cortinal de San Juan (Salvatierra de Tormes, Salamanca).

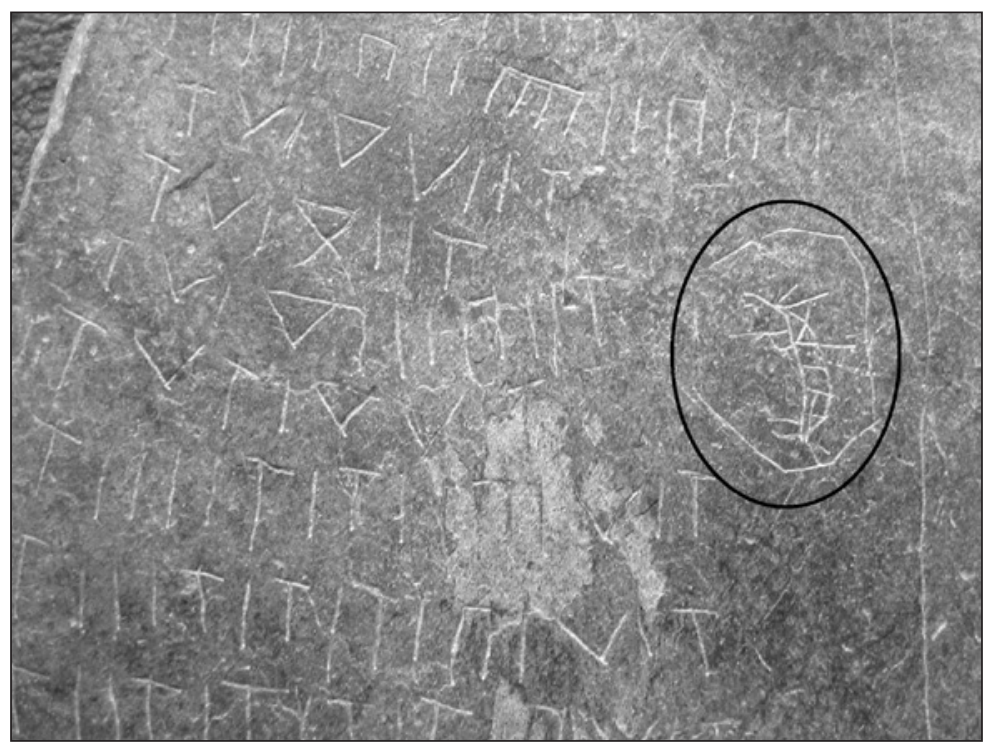

FIGURA 6

Pizarra numérica con representación de un animal, procedente de Lerilla (Zamarra, Salamanca).

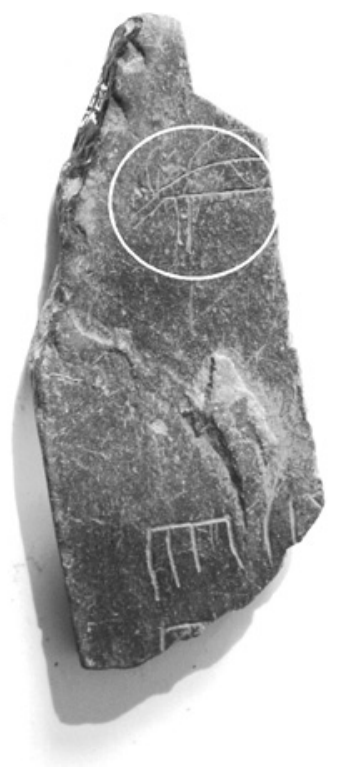


Por tanto, las oficinas contables serían la huella de un control sobre el territorio ejercido por las elites asociadas a esos castella, articulado como un dominio sobre procesos productivos ajenos mediante argumentos que podríamos calificar como "políticos". Son el auténtico referente de la autoridad y, en calidad de tales, ejercen un dominio, tasado posiblemente en una tributación indirecta, sobre las comunidades que habitan su territorio. Esto explica a su vez la presencia de pizarras en centros urbanos, que funcionarían como lugares de concentración de excedentes en forma de tributo. La razón por la que en lugares como Ávila no se han documentados grandes concentraciones de pizarras, como las que caracterizan a algunos castella, podría ser un indicio de un tipo de dominio diferente y propio de los centros urbanos, aunque resulta más probable que sea simplemente una distorsión provocada por la intensa ocupación del espacio ${ }^{46}$. En cualquier caso, los datos pueden interpretarse en el sentido de que buena parte de las funciones tributarias de las ciuitates se encontraban en manos de los grupos que dominaban los castella.

\section{Pizarras y poblados campesinos}

El análisis de los contextos en los que han aparecido pizarras permite afirmar que son una huella del poder. Cuando se detecta una alta concentración de hallazgos, podemos hablar de lugares en los que se focaliza un dominio político, basado en el tributo indirecto. Por otra parte, la pluralidad de situaciones responde al fenómeno de multiplicación de focos de poder que caracteriza el periodo postromano en todo el Mediterráneo Occidental ${ }^{47}$. Sin embargo, disponemos de numerosos hallazgos aislados, de pocas pizarras, procedentes de sitios rurales que no pueden definirse como "lugares centrales". Muchos de tales hallazgos son bastante antiguos y desconocemos el contexto en el que se recogieron. Otros han sido fruto de la casualidad y podrían relacionarse con el arrastre de materiales o su reutilización, una vez despojadas las pizarras de su función inicial. No obstante, hay casos en los que disponemos de algo más de información, como ocurre en el lugar de Santa Margarida (Serpa, Portugal). Este lugar fue objeto de una prospección de superficie que, junto a materiales calcolíticos, romanos e islámicos, proporcionó un pequeño fragmento de pizarra numérica cerca de una posible estructura donde aparece cerámica de construcción, pero no sigillata, lo que parece

46 En cambio, para Los Azafranales, en Coca, se ha planteado la posibilidad de una oficina contable. Juan Francisco Blanco García, "Coca arqueológica", Revista de Arqueología, 81 (1988), p. 55.

47 Cristina La Rocca, "La trasformazione del territorio in Occidente", Morfologie sociali e culturali in Europa fra Tarda Antichità e Alto Medioevo, Centro Italiano di Studi sull'alto Medioevo, Spoleto, 1998, vol. I, pp. 257-290. Laurent SCHNEIDER, "Cités, campagnes et centres locaux en Gaule narbonnaise aux premiers siècles du Moyen Âge (Ve-IX ${ }^{\mathrm{e}} \mathrm{s}$.): une nouvelle géographie, de noveux liens”, Villes et campagnes de la Tarraconaise et d'al-Andalus (VIe-IXesiècle): la transition, Philippe Sénac (ed.), Universitè de Toulouse-Le Mirail, Toulouse, 2007, p. 19. 
situarnos ante algún tipo de asentamiento de época postromana ${ }^{48}$. De todos modos, no se puede avanzar más en la definición del lugar ante la ausencia de más datos ${ }^{49}$. Sin embargo, en los últimos años, han surgido nuevos hallazgos en poblados campesinos con contextos estratigráficos mejor documentados. Un buen ejemplo es el yacimiento de La Genestosa (Casillas de Flores, Salamanca). Este lugar ha sido objeto de una atención especial dentro de un proyecto destinado a comprender la formación de los paisajes medievales a escala local a través del estudio de los espacios funerarios definidos por la presencia de tumbas excavadas en la roca ${ }^{50}$. El sitio se halla en el extremo suroccidental de la provincia de Salamanca a apenas un kilómetro en línea recta de la frontera con Portugal, en la subcomarca de El Rebollar, a unos $35 \mathrm{kms}$ al sur de Ciudad Rodrigo, la cabecera comarcal. El arroyo del Mazo de Prado Álvaro, un cauce fluvial estacional típico del área de penillanuras paleozoicas en donde se emplaza La Genestosa, articula el territorio de Oeste a Este hasta su desembocadura en el río Águeda, el principal colector de esta comarca. A lo largo de cinco kilómetros, el arroyo crea en sus márgenes una estrecha franja de suelos de mayor potencialidad agroganadera, que contrastan con la acidez propia de los suelos graníticos de todo este sector. En torno al cauce, se ha podido reconocer la presencia de una serie de tumbas excavadas en la roca, en total 21, que aparecen aisladas o formando pequeños grupos, todas ellas situadas en el glacis del arroyo, fuera de las zonas inundables. Junto a estas tumbas, se identifican en superficie restos de edificaciones formadas por zócalos de doble paramento de granito, con relleno en su interior. Tales estructuras forman pequeños núcleos que se localizan en torno al arroyo (Fig. 7$)^{51}$.

\footnotetext{
48 Catarina Tente y António Soares, "Uma pizarra visigoda...".

49 Una situación semejante a la del hallazgo de una pizarra con texto, posiblemente de la segunda mitad del siglo X, en Fuente Encalada. Ángel Esparza Arroyo y Ricardo Martín Valls, "La pizarra altomedieval..."

so Sobre la perspectiva del proyecto, Iñaki MARTín Viso, "Enterramientos, memoria social y paisaje en la Alta Edad Media: propuestas para un análisis de las tumbas excavadas en roca en el centro-oeste de la península ibérica', Zephyrus, 68 (2012), pp. 165-187. Una visión sobre la zona y sus formas de poblamiento en Rubén Rubio Díez, "Tumbas excavadas en roca y poblamiento rural postromano al suroeste del Duero", Arqueología en el valle del Duero. Del Neolítico a la Antigüedad Tardía: nuevas perspectivas, José Carlos Sastre, Raúl Catalán y Patricia Fuentes (eds.), La Ergástula, Madrid, 2013, pp. 269-280. Sobre La Genestosa, véase Iñaki MARTín VIso, "Paisajes sagrados, paisajes eclesiásticos. De la necrópolis a la parroquia en el centro de la península ibérica", Reti Medievali. Rivista, 12:2 (2012), pp. 19-20 [DOI: 10.6092/1593-2214/362].

${ }^{51}$ Para una descripción de las características del área del arroyo del Mazo de Prado Álvaro, aunque con datos previos a las excavaciones de 2012 y 2013, Enrique Paniagua Vara y Alicia Álvarez Rodríguez, "Tumbas excavadas en roca y poblamiento altomedieval en Casillas de Flores y El Payo (Salamanca). Primeros resultados a partir de una prospección', Arqueología en el valle del Duero. Del Neolítico a la Antigüedad Tardia: nuevas perspectiva, José Carlos Sastre, Raúl Catalán y Patricia Fuentes (eds.), La Ergástula, Madrid, 2013, pp. 299-306.
} 
FIGURA 7

La articulación del territorio en torno al arroyo del Mazo de Prado Álvaro (Casillas de Flores, Salamanca).

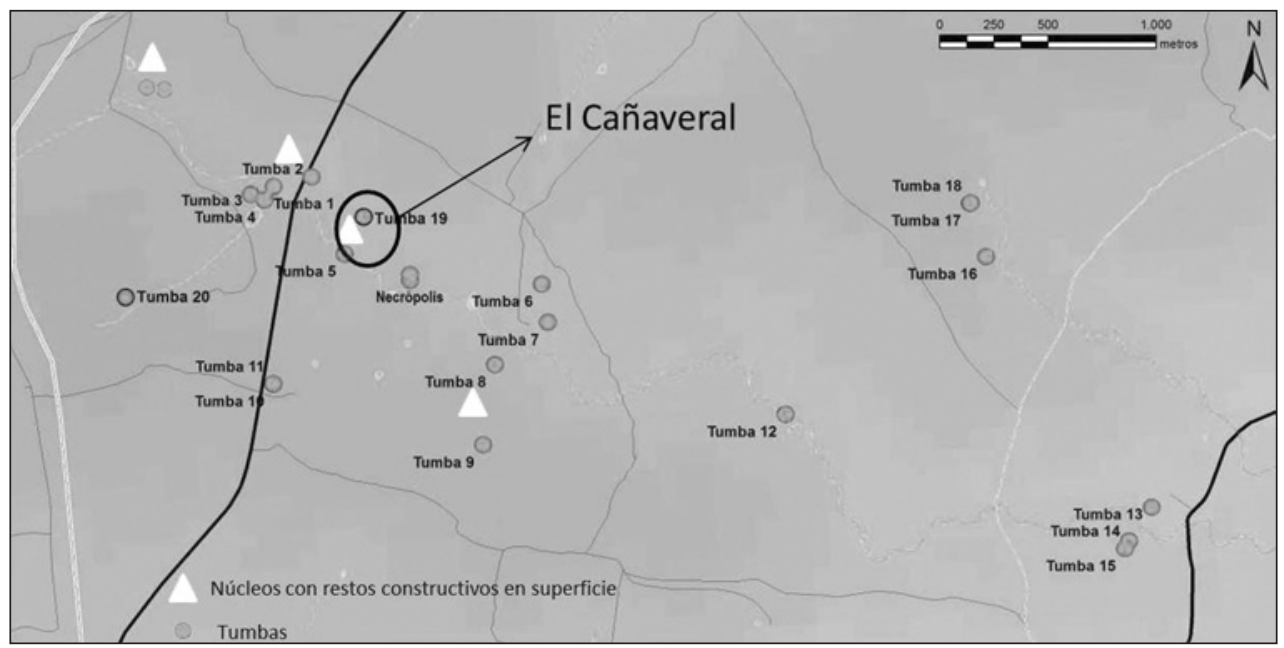

En uno de esos núcleos, emplazado dentro de la dehesa de La Genestosa, en el pago denominado El Cañaveral, se han efectuado dos campañas de excavación en los años 2012 y $2013^{52}$. Los resultados ponen de relieve la existencia de un núcleo de unas doce estructuras, posiblemente residenciales, definido por sendas escorrentías, y emplazado cerca del arroyo del Mazo de Prado Álvaro, pero sobre el glacis del mismo (Fig. 8). Se han excavado dos de las construcciones que muestran una edilicia semejante a la ya descrita -por otro lado típica de la zona ${ }^{53}$ - y se ha recuperado un amplio conjunto cerámico, de cerca de 3000 fragmentos, en el que abundan las cerámicas domésticas, quizás hechas a torneta, lo que, unido a la presencia de tegula, parece indicarnos una ocupación entre los siglos V a VII. Esta cronología se refuerza con el hallazgo en la campaña de 2013 de un fragmento de cerámica estampillada ${ }^{54}$. Por otra parte, una de las dos estructuras (la 4) posee una secuencia más compleja, pues se ha podido detectar una ocupación de época altoimperial (siglos I-II d.C.) con una construcción con muros mejor trabajados, que formaban una edificación orientada de distinta forma a la postromana, y con algunas sigillatas recuperadas. No obstante, parece existir un

52 Para los resultados de la primera campaña, véase Iñaki MarTín Viso y Rubén RuBio Díez, Primera campaña de excavación arqueológica en el yacimiento de La Genestosa (Casillas de Flores, Salamanca), Salamanca, 2013 [Informe inédito].

53 Carlos TeJERIzo, "Early medieval household archaeology in Northwest Iberia $\left(6^{\text {th }}-11^{\text {th }}\right.$ centuries)", $A r$ queología de la Arquitectura, 9 (2012), pp. 186-190.

54 Esta cerámica es sin duda del siglo V, pero su uso pudo extenderse a periodos posteriores, incluyendo todo el horizonte postromano. Enrique ArIÑo, "El yacimiento de El Cortinal de San Juan...", p. 267; Sarah Dahí Elena, Contextos cerámicos de la Antigüedad tardía y la Alta Edad Media (siglos IV-VIII d.C.) en los asentamientos rurales de la Lusitania septentrional (provincia de Salamanca), Archaeopress, Oxford, 2012. 
hiato ocupacional entre el siglo II y el V, por lo que puede conjeturarse que a partir de ese último momento se produce una nueva ocupación de un espacio deshabitado o desfuncionalizado, al que se une una fuerte transformación del asentamiento y de la ocupación del territorio. En tal sentido, y ante la ausencia de evidencias de elites, cabe suponer que los protagonistas directos fueron grupos campesinos, que se establecieron sobre áreas hasta entonces marginales. Una posible estrategia para reclamar derechos de uso sobre espacios hasta entonces marginales, así como para formar una identidad del grupo residente, pudo ser el recurso a la memoria de ancestros prestigiosos. Eso explicaría la cercanía de las tumbas a los núcleos habitados. En el caso de El Cañaveral, aparece una sepultura excavada en roca a apenas 17 metros de la estructura 4, aunque fuera ya del núcleo habitado, que pudo tener esa funcionalidad ${ }^{55}$.

FIGURA 8

Topografía del lugar de El Cañaveral, en la dehesa de La Genestosa (Casillas de Flores, Salamanca).

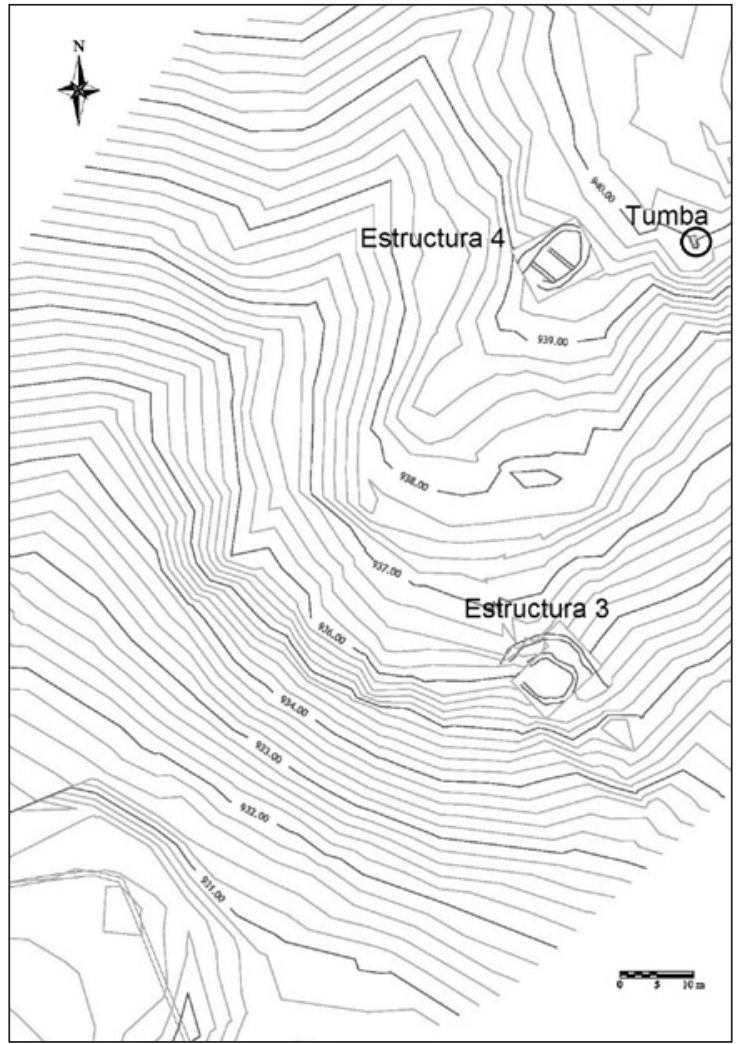

55 Iñaki MArTín Viso, "Enterramientos, memoria social y paisaje..." y "Ancestors and landscape: early medieval burial sites in the central-western region of the iberian peninsula" (en prensa). 
En la estructura 4, se hallaron ocho pequeños fragmentos de pizarras numéricas, cuya descripción detallada figura en un anexo. Concretamente en la UE 408, que se corresponde con un derrumbe procedente de la construcción postromana, se encontraron cinco fragmentos de pizarra con inscripciones numéricas. Se trata de varios fragmentos de una misma pieza, de color grisáceo claro y que aparece muy exfoliada. El mal estado de preservación, debido a la exfoliación, ha impedido la conservación de líneas completas, pero las características se asemejan a las que se conocen en otros casos, incluyendo el rasgo más destacado como es la presencia de trazos horizontales que separan cada una de las líneas en forma de renglones. Por otro lado, en la UE 410, que corresponde a otro nivel de derrumbe de la misma estructura, se encontraron otros tres fragmentos de pizarras numéricas. Su estudio permite plantear la existencia de otras piezas además de la que procede de la UE 408, e incluso parece que estamos ante dos piezas diferentes. Por tanto, estaríamos ante ocho pequeños fragmentos de tres piezas diferentes (Figs. 9 y 10).

\section{FIGURA 9}

Pizarra numérica $\mathrm{n}^{0} 2$, procedente de la UE408 de La Genestosa.
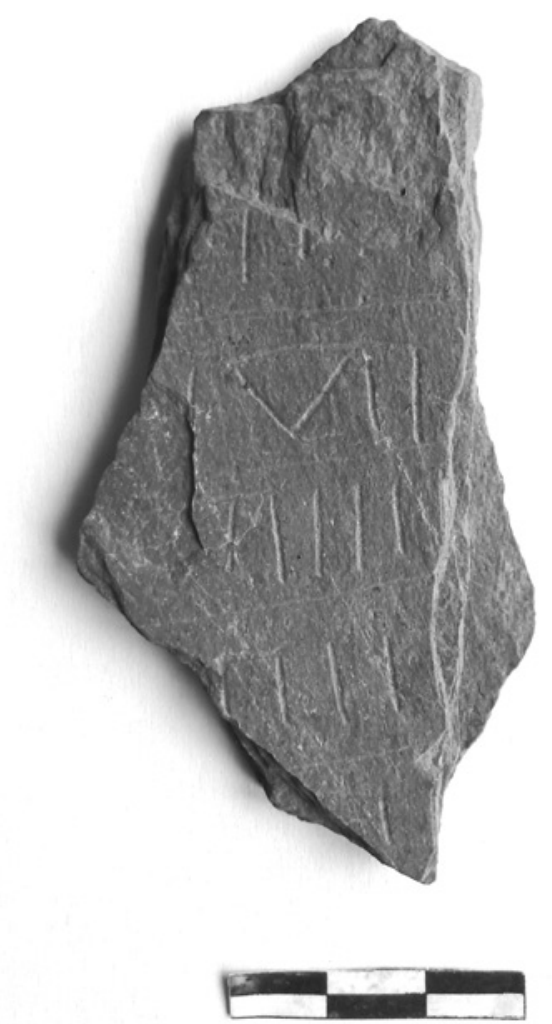

Figura 10

Pizarra numérica $\mathrm{n}^{\circ} 8$, procedente de la UE410 de La Genestosa.

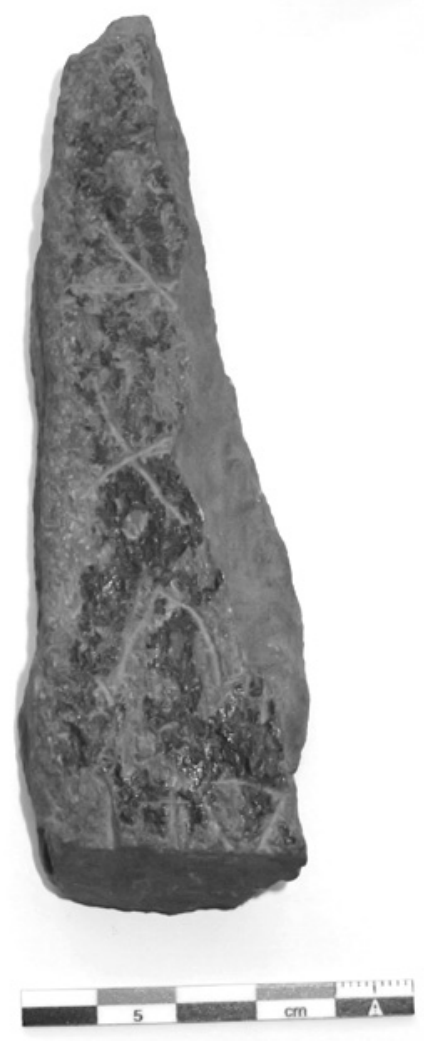


La Genestosa no es el único caso de poblado campesino en el que se ha recuperado pizarras. El Pelícano (Arroyomolinos, Madrid) es un poblado rural abierto que se extiende a lo largo de un arroyo en forma de una serie de granjas, con una cronología entre mediados del siglo V y mediados del siglo VIII. La edilicia es sencilla, con estructuras construidas con zócalos de piedra y construcciones semienterradas o fondos de cabaña, y la cerámica recuperada es de carácter doméstico, sin complejidades técnicas ni elementos de importación. Los rasgos indican, por tanto, un asentamiento rural ocupado por campesinos ${ }^{56}$. En el sector 9 de ese yacimiento, en un contexto fechable hacia finales del siglo $\mathrm{V}$ o primera mitad del VI (UE 9093), se encontró un pequeño fragmento de pizarra con texto escrito, de la que únicamente se conservan algunas letras y no se ha podido descifrar su sentido ${ }^{57}$. Otro caso es el yacimiento de La Cárcava de la Peladera (Hontoria, Segovia). El lugar se encuentra en el espacio periurbano de la ciudad de Segovia, que fue sede episcopal durante el periodo visigodo. El poblado está formado por una serie de estructuras semienterradas, junto con espacios productivos, y parece relacionarse con una necrópolis cercana, aunque ya desaparecida. Los restos recuperados nos hablan de producciones domésticas y de una cronología entre los siglos V al VII para este poblado campesino ${ }^{58}$. En este sitio, se recuperaron dos fragmentos de pizarras numéricas, correspondientes a dos piezas distintas y de pequeñas dimensiones $(9,8 \times 6,5 \times 0,8 \mathrm{cms} \text { y } 8,5 \times 6,2 \times 0,5 \mathrm{cms} \text { respectivamente })^{59}$. Por último, hay que señalar el sitio de Las Henrrenes (Cillán, Ávila). Se halla en la zona de la Sierra de Ávila, cruzado por la Cañada Real Soriana Occidental, que divide el lugar en dos sectores (Fig. 11). Las diversas intervenciones realizadas han permitido exhumar un conjunto de viviendas construidas con zócalos de piedra y una cultura material típica de los asentamientos rurales campesinos con abundante cerámica doméstica hecha a torneta y algunos elementos de metalistería ${ }^{60}$. La campaña de 2013 se centró en una de las estructuras residenciales. En el derrumbe al exterior de uno de los muros de esa estructura, se localizó un pequeño fragmento de 10 × 6,9 × $1,2 \mathrm{cms}$ con algunas grafías numéricas. Por otro lado, en el derrumbe de otro de los muros, se encontró un nuevo fragmento de características similares de $10 \times 6,6 \times 1,2 \mathrm{cms}^{61}$.

\footnotetext{
56 Alfonso Vigil-Escalera Guirado, "Las aldeas altomedievales madrileñas y su proceso formativo", The archaeology of early medieval villages in Europe, Juan Antonio Quirós Castillo (ed.), Universidad del País Vasco, Bilbao, 2009, pp. 321-328 Alfonso Vigil-Escalera Guirado, "El Pelícano (Arroyomolinos, Madrid)", El poblamiento rural de época visigoda en Hispania. Arqueología del campesinado en el interior peninsular, Juan Antonio Quirós Castillo (ed.), Universidad del País Vasco, Bilbao, 2013, pp. 177-201.

57 Aránzazu Urbina Álvarez, "Pizarras con inscripción...".

58 Strato, "La Cárcava de la Peladera", El poblamiento rural de época visigoda en Hispania. Arqueología del campesinado en el interior peninsular, Juan Antonio Quirós Castillo (ed.), Universidad del País Vasco, Bilbao, 2013, pp. 101-116.

59 Strato, "La Cárcava...", p. 113.

60 Para una descripción del yacimiento, véase Jorge Díaz de la Torre, María Bores Ureta, Jesús Caballero Arribas y Blas CABrera GonzÁlez, "El despoblado de San Cristóbal o Las Henrrenes (Cillán, Ávila): una aproximación al paso de la Edad Antigua a la Edad Media en tierras abulenses", ¿Tiempos oscuros? Territorio y sociedad en el centro de la península ibérica (siglos VII-X), Iñaki Martín Viso (ed.), Sílex, Madrid, 2009, pp. 159-180. ${ }_{61}$ Castellum S. Coop., Informe de las Investigaciones Arqueológicas (IV Campaña, 2013) en el yacimiento de Las Henrenes (Cillán, Ávila), Castellum S. Coop., Ávila, 2013 [Informe inédito]. Agradezco a Jorge Díaz de la Torre por haberme proporcionado esta interesantísima información.
} 


\section{FIGURA 11}

Estructuras de Las Henrrenes (Cillán, Ávila).

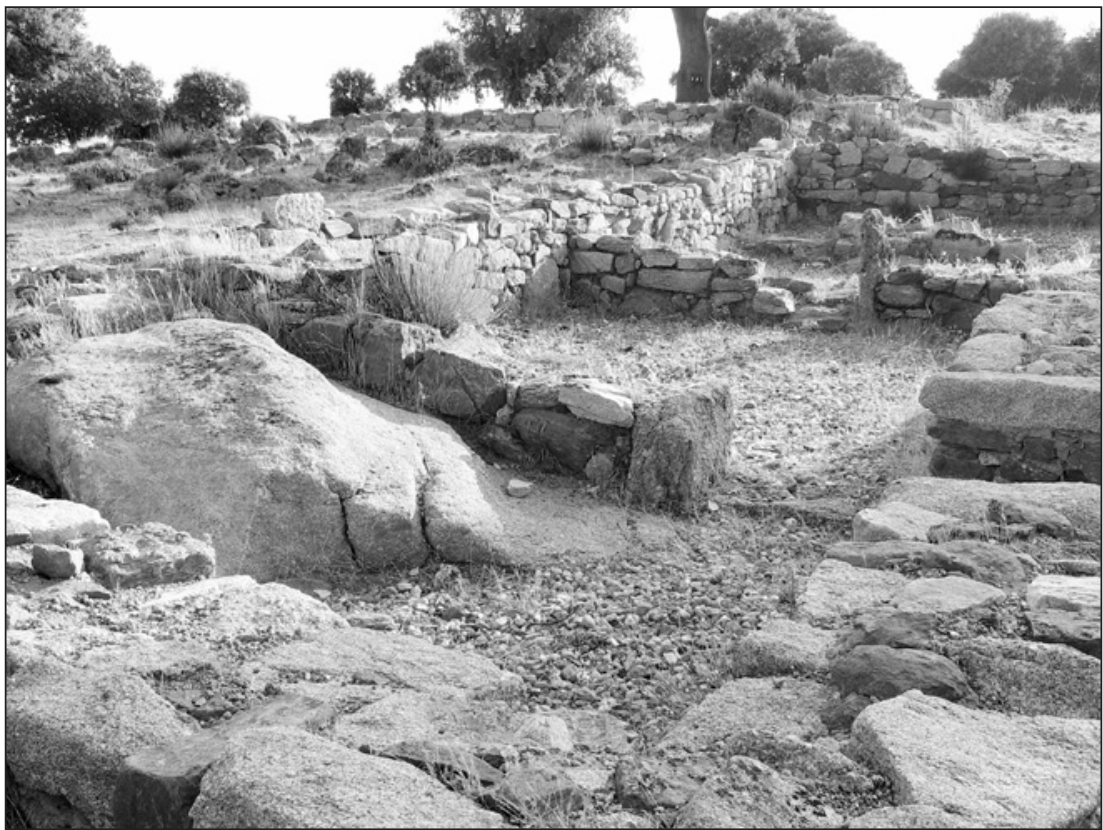

Estos cuatro casos nos permiten acercarnos con mayor exactitud a la existencia de pizarras en contextos campesinos. La escasez de yacimientos de estas características que hayan sido objeto de intervención en el centro peninsular los convierte en ejemplos de una situación que posiblemente fuese más común, como ocurre en el sureste de la provincia de Valladolid, donde se han encontrado algunas pizarras numéricas en varios lugares ${ }^{62}$. Así sucede en La Llosa, cerca de Íscar, con abundante material cerámico tardorromano y postromano ${ }^{63}$; en Los Nuevos, que posiblemente sea el lugar de El Valle, situado entre Quintanilla de Arriba y Cogeces del Monte, donde apareció una pizarra publicada en 1976 ${ }^{64}$; y en Dehesa del Aguasal ${ }^{65}$. Si estuviéramos ante poblados campesinos, aunque solo poseemos datos de superficie, habría que inferir que el fenómeno de la presencia de pizarras en contextos campesinos debió ser mucho más extenso.

62 Ma Victoria Calleja Martínez, "El poblamiento de época visigoda...".

63 Tomás Mañanes Pérez, Arqueología del área central de la cuenca del río Duero: de Simancas a Coca, Diputación de Valladolid, Valladolid, 2002, pp. 107-109.

$64 M^{a}$ Francisca Represa Fernández, "Una pizarra visigótica del tipo Lerilla", Boletín del Seminario de Estudios de Arte y Arqueología, XLII (1976), pp. 453-457.

65 Tomás Mañanes Pérez, Arqueología del área central..., p. 77. 


\section{Hacia una interpretación de los hallazgos}

La consecuencia de estos hallazgos es una aparente paradoja. Las pizarras son básicamente un marcador de dominio social, que aparece sobre todo en los lugares donde se expresa el poder. Sin embargo, ¿cómo entender su presencia en poblados campesinos, que de ninguna forma pueden interpretarse como espacios relacionados directamente con el poder? Esta contradicción ha sido acertadamente señalada por Alfonso VigilEscalera y Juan Antonio Quirós que se preguntan si son el testimonio de prácticas contables por parte de propietarios residentes o no, si eran instrumentos mediante los cuales las elites campesinas expresaban materialmente su dependencia con respecto a esferas políticas superiores y si serían una muestra de la penetración de las prácticas de la contabilidad de la gran propiedad en contextos mayoritariamente campesinos ${ }^{66}$. En este último sentido, algunos investigadores han puesto el acento en el hecho de que la gran difusión de estas pizarras sería una prueba de la extensión de una cultura de lo escrito, de herencia romana, que habría continuado en el periodo postromano a través de personas con unos conocimientos rudimentarios, pero suficientes ${ }^{67}$. Esas apreciaciones se basan en el análisis de las pizarras con textos escritos, más reducida que en el caso de las pizarras numéricas. Este aspecto es de enorme interés, pero se aleja de nuestro foco de atención. Sin ánimo de analizar en profundidad esa posibilidad, hay que señalar que la existencia de algunas pizarras numerales en asentamientos campesinos no es una prueba en sí misma de la presencia de niveles de alfabetización propios de ese lugar, como veremos. En cambio, la alta concentración en un determinado lugar, podría ser un testimonio de esa alfabetización.

Recientemente, se ha señalado para el caso de la península ibérica la posibilidad de interpretar algunos elementos del registro arqueológico procedente de poblados campesinos como marcadores que permiten adentrarse en la configuración de jerarquías sociales dentro de esos contextos: el uso de objetos exóticos o de prestigio, las pautas de consumo y los patrones de producción, así como el ejercicio del poder en el diseño de los asentamientos y paisajes mediante el almacenamiento y/o la organización del terrazgo ${ }^{68}$. La presencia de pizarras ha de interpretarse como uno de esos marcadores, que se incluiría en el tercero de los grupos. Para ello, conviene fijarse en algunos rasgos que caracterizan los hallazgos en estos poblados.

\footnotetext{
66 Alfonso Vigil-Escalera Guirado y Juan Antonio Quirós Castillo, "Un ensayo de interpretación del registro arqueológico", El poblamiento rural de época visigoda en Hispania. Arqueología del campesinado en el interior peninsular, Juan Antonio Quirós Castillo (ed.), Universidad del País Vasco, Bilbao, 2013, p. 396.

67 Manuel C. DíAz y Díaz, "Problemas culturales en la Hispania tardorromana y visigoda", De la Antigüedad al Medievo. Siglos IV-VIII, Fundación Sánchez-Albornoz, Ávila, 1993, pp. 30-31; Isabel Velázquez SoriAno, "La cultura gráfica en la Hispania visigoda: las escrituras anónimas", Visigoti e longobardi, Javier Arce y Paolo Delogu (eds.), All'Insegna del Giglio, Florencia, 2001, p. 195; Isabel Velázquez Soriano, Las pizarras visigodas..., p. 50; José $\mathrm{M}^{a}$ Ruiz AsEnCIO, "Nuevos hallazgos de documentos visigodos en pizarra", Archivos Leoneses, 93-94 (1993), p. 13.

68 Juan Antonio Quirós CASTILlo, "Archaeology of power and hierarchies in early medieval villages in Northern of Spain", Hierarchies in rural settlements. Ruralia IX, Jan Klápště (ed.), Brepols, Turnhout, 2012, pp. 199-212.
} 
En primer lugar, cabe destacar el bajo número de piezas que se han encontrado, sobre todo en comparación con las grandes concentraciones que definen a algunos de los "lugares centrales" considerados paradigmas de los hallazgos de pizarras numéricas, como Lerilla, El Cortinal de San Juan e incluso La Cabeza de Navasangil. Puede argumentarse que este dato podría estar distorsionado porque ha habido una intensa ocupación de esos espacios campesinos, lo que ha podido conllevar la amortización o desaparición de pizarras. Sin embargo, esos mismos procesos afectaron a los sitios con concentración de pizarras: El Cortinal de San Juan se encuentra a unos pocos metros del castillo y la cerca de la villa de Salvatierra de Tormes, de cierta relevancia en época pleno y bajomedieval ${ }^{69}$, y un lugar con ocupación hasta nuestros días. Por otra parte, La Cabeza de Navasangil sufrió un fuerte incendio, que se atestigua incluso en las pizarras recuperadas, que presentan síntomas evidentes de haber sido sometidas al fuego ${ }^{70}$. Por consiguiente, la ausencia de concentración de pizarras no tiene por qué responder a una distorsión producto de los procesos posdeposicionales, sino que es más bien el reflejo de una realidad: en estos poblados no existieron oficinas contables que sirvieran como focos de una captación constante.

Un aspecto relevante es que cuando disponemos de una información precisa sobre cómo aparecieron las pizarras, estas se localizan en derrumbes (La Genestosa, Las Henrrenes). No se han hallado como materiales archivados, sino como objetos ya desfuncionalizados, quizá formando parte de elementos constructivos o simplemente de la basura del asentamiento. Por tanto, no eran el producto de una situación que exigiera de manera constante una contabilidad, sino que parece algo puntual. Debe tenerse en cuenta que en tres de los cuatro casos nos encontramos con pizarras numéricas, las cuales, como se ha indicado, eran más bien un tipo de documento que contabiliza in situ unidades homólogas de lo que fuese, que posiblemente servía para elaborar a posteriori otro documento. Era un registro contable de uso inmediato y rápida amortización, es decir un documento de usar y tirar, no destinado a su archivo, tal y como ocurría con las pizarras escritas $^{71}$. En el caso de los poblados campesinos, parece que tuvo una utilidad inmediata y un carácter puntual, no constante. Es distinto el caso de la pizarra de El Pelícano, al tratarse de un texto, que no ha podido descifrarse por la extrema fragmentación de la pieza recuperada. ¿Estamos ante la misma situación que en los hallazgos de pizarras numéricas? Quizá la presencia de esta pizarra no deba interpretarse de la misma forma que los hallazgos de pizarras numéricas y haya que pensar en algún tipo de documento de archivo, al menos como conjetura.

Otro aspecto llamativo es que en todos los casos la pizarra no es un material local, sino que procede de otros ámbitos. Un buen ejemplo es La Genestosa, que se emplaza en un

\footnotetext{
69 José Ma Monsalvo Antón, "Panorama y evolución jurisdiccional en la Baja Edad Media", Historia de Salamanca, II. Edad Media, José Ma Mínguez (coord.) y José Luis Martín (dir.), Centro de Estudios Salmantinos, Salamanca, 1997, pp. 351-352.

70 Hortensia Larrén Izquierdo, "Materiales cerámicos de La Cabeza: Navasangil (Ávila), Boletín de Arqueología Medieval, 3 (1989), pp. 53-74; Jesús Caballero Arribas y David Peñas Pedrero, "Un castrum de época visigoda...”.

71 Hipótesis ya desarrollada por Iñaki MARTín VISO, “The Visigothic slates...”.
} 
entorno granítico; sin embargo, más al Este, en la ribera derecha del río Águeda, los suelos se vuelven pizarrosos. Llama la atención que es precisamente en esa zona, unos kilómetros aguas abajo, donde se encuentra Lerilla, un castellum bien conocido por la abundancia de pizarras numéricas, sean o no todas ellas procedentes de este lugar, si bien hay que pensar que una buena parte de las piezas habrían sido recogidas allí. Esta situación se repite en los otros poblados. El Pelícano se encuentra en un sector de suelos sedimentarios y las pizarras se encuentran en la Sierra Norte de la Comunidad de Madrid. En el caso de La Cárcava de la Peladera, no hay evidencias cercanas de suelos pizarrosos, lo que también sucede en el caso de Las Henrrenes, lugar emplazado en un área predominantemente granítica. Por tanto, la presencia de pizarras en espacios donde no hay este tipo de material parece estar encubriendo la existencia de redes de producción y distribución de este soporte, que probablemente se ha conservado frente a lo que pudo haber sucedido con otros materiales más perecederos ${ }^{72}$. Esta observación acerca del carácter "externo" de las pizarras ya se ha señalado en otras ocasiones con respecto a casos concretos ${ }^{73}$. Pero es realmente interesante advertir cómo lugares con una alta concentración de pizarras (como parece ser Lerilla y sobre todo El Cortinal de San Juan) se emplazan en espacios con suelos pizarrosos, aunque no es necesariamente un patrón general, pues no sucede así con La Cabeza de Navasangil. De todos modos, cabe plantearse si, al menos en el caso de La Genestosa, estaríamos ante una evidencia de un flujo desde un "lugar central", donde se usa la pizarra de manera masiva gracias a su presencia local, hacia un poblado campesino. La hipótesis concuerda con el resto de los datos de los que disponemos. En otros casos, el soporte (la pizarra) podría provenir de zonas que, mediante redes de distribución, llegarían a determinados puntos donde se precisaba de dicho soporte (por ejemplo, Ávila) y desde esos centros llegaría la pizarra hasta los poblados campesinos (por ejemplo, Las Henrrenes). Sea como fuere, parece evidente que la presencia de pizarras en lugares donde no es un material local implica una conexión externa.

Las conclusiones de estos datos suponen que no estamos ante focos de una contabilidad constante, como ocurría en los castella o en las ciudades, e incluso en puntos rurales asociados a una importante actividad productiva. Por el contrario, no encontraríamos ante la evidencia de un ejercicio puntual, que en ningún caso derivó en la formación de un archivo. Tampoco implica necesariamente una alfabetización bien difundida, pues se trata de piezas que pueden reflejar la presencia de individuos procedentes de fuera de los asentamientos y que, en general, muestran una habilidad matemática, que no tiene por qué incluir de forma automática -aunque no las excluye- otro tipo de habilidades lectoras o escriturísticas ${ }^{74}$.

\footnotetext{
72 Alfonso Vigil-Escalera Guirado y Juan Antonio Quirós Castillo, “Un ensayo de interpretación...”, p. 396.

$73 \mathrm{M}^{\mathrm{a}}$ Francisca Represa Fernández, "Una pizarra visigótica...", p. 452; Tomas Cordero Ruiz e Iñaki MarTín Viso, "Sobre los usos y la cronología...", p. 258.

74 Podría argumentarse que en Los Marvanes (Mogarraz, Salamanca) se han encontrado una serie de pizarras con textos con contenidos muy diversos, que se sumarían al hallazgo de una pizarra numeral en el mismo pago, así como otras en el municipio de Mogarraz; José Ma Ruiz Asencio, "Nuevos hallazgos..." y "Pizarra visigoda con credo", Estudios dedicados a José Ma Fernández Catón, Manuel C. Díaz y Díaz (coord.), Centro de Estudios San Isidoro, León, 2004, vol. II, pp. 1317-1328. Sin embargo, carecemos de una información
} 
¿Cómo explicar entonces la presencia de estas pizarras? Por desgracia, debemos movernos en el terreno de la hipótesis. La más convincente es que estas pizarras, al menos las numéricas, fueran la consecuencia de una captación in situ de un excedente, que, sin embargo, no se nos especifica ${ }^{75}$. Esta captación debió hacerse de manera puntual, a tenor de la escasez de piezas (o fragmentos de ellas) que se han podido recuperar, en lo que parece ser un patrón bastante común. De los casos estudiados, allí donde se encuentran más posibles pizarras es en La Genestosa, con un total de tres posible piezas, de las que quedan ocho fragmentos. Se trata de una situación generalizada que explica el hallazgo de numerosas piezas numéricas aisladas en buena parte de la geografía del centro peninsular. Esta captación puntual procede de fuera del asentamiento, como parecería indicar el hecho de que la pizarra no sea un producto local; al menos hay que pensar en redes de distribución y de uso de un material que no aparece en todas partes. De nuevo, el caso de La Genestosa es muy interesante, ya que la pizarra podría porvenir de un ámbito cercano, pero asociado a la presencia de un "lugar central" como es Lerilla. Por tanto, podría entenderse como un indicio de una captación relacionada con ese "lugar central", donde se utilizaba la pizarra como soporte gracias a que era un material local. Las pizarras de La Genestosa se localizaron además en un punto concreto, en los derrumbes de la estructura 4. Por tanto, no parece ser un material frecuente en todas las estructuras, sino que se concentra en un determinado lugar, quizá donde se llevó a cabo esa contabilidad.

Por consiguiente, las pizarras encontradas en poblados campesinos serían la consecuencia de una captación basada en un dominio puntual, lo que se ajusta al modelo explicativo de unas elites locales que disfrutaban de un poder de tipo "político", capturando tributos y controlando procesos productivos externos a ellas ${ }^{76}$. Las pizarras con textos escritos parecen avalar una situación de ese tipo, pues la propiedad fundiaria se mueve en ámbitos locales ${ }^{77} \mathrm{y}$ son frecuentes las menciones a posibles pagos de tipo tributario ${ }^{78}$. Los castella debieron ejercer una considerable centralidad a la hora de articular ese dominio en el centro peninsular, lo que explica la presencia de oficinas contables. Pero eso no

arqueológica clara del tipo de yacimiento, que no ha sido objeto de intervención alguna. Debe recordarse que en esta misma comarca, nos encontramos con el lugar de La Legoriza, que más que un asentamiento campesino, debe entenderse como un lugar de producción o quizá mejor como un asentamiento creado en torno a un importante punto de producción. A ello se añade la relevancia de la actividad oleícola patente en otro yacimiento cercano como es El Cuquero; Enrique Ariño, Lorenzo Barbero y Pablo de la Cruz DíAz, P. C., "El yacimiento agrícola de El Cuquero y el modelo de poblamiento en época visigoda en el valle del río Alagón”, Lancia, 6 (2004-05), pp. 205-231. Por consiguiente, no se puede asegurar que el yacimiento de Los Marvanes presente una tipología específica de asentamiento campesino y quizá haya que pensar en una situación en la Sierra de Francia salmantina muy específica, con lugares en los que se observa una fuerte actividad productiva.

75 Esta idea de una captación in situ, aunque aplicada a las pizarras con texto, ya la desarrolla Félix ReTAMERo, La contínua il-lusió del moviment perpetu. La moneda dels reges, dels mulūk $i$ dels seniores (segles VI-XI), Universitat Autònoma de Barcelona, Barcelona, 2000, pp. 171-172.

76 Iñaki MarTín VISO, "La ordenación del territorio rural...”, pp. 253-257 y “Castella y elites...”, pp. 266-267.

77 C. Wicкнам, Framing the Early Middle Ages. Europe and the Mediterranean, 400-800, Oxford University Press, Oxford, pp. 223-225; Iñaki MARTín VISo, "La sociedad rural en el suroeste de la Meseta del Duero (siglos VI-VII)", Espacios de poder y formas sociales en la Edad Media. Estudios dedicados a Ángel Barrios, Gregorio del Ser Quijano e Iñaki Martín Viso (eds.), Universidad de Salamanca, Salamanca, 2007, pp. 177-178.

78 Iñaki MARTín VISO, “Tributación y escenarios locales...” y "La sociedad rural...". 
obsta para que hubiera más "lugares centrales" (centros eclesiásticos, ciuitates...) que podrían estar actuando en un paisaje caracterizado por la heterogeneidad ${ }^{79}$.

Si esta hipótesis es correcta, las pizarras en poblados campesinos mostrarían las conexiones entre la esfera de las elites locales y la de las comunidades campesinas. Podría tratarse de un marcador visible de ese dominio, uno más entre otros de momento invisibles. Ahora bien, carecemos de evidencias claras sobre esos otros marcadores, por lo que con el registro que disponemos -a pesar de ser incompleto y parcial- parece más factible pensar en unas comunidades dotadas de una gran autonomía con respecto a la forma de organizarse ${ }^{80}$, pero que estaban conectadas con las aristocracias. Por tanto, son huellas del poder ${ }^{81}$, aunque con unas características específicas, como hemos visto, y que debieron ser reconocidas por la monarquía de Toledo cuando a partir de finales del siglo VI implementó su control sobre este sector. Estas huellas reflejarían un poder que llega, cuenta aquello que se lleva (por una legitimación real o de facto) y se marcha, es decir un poder que puntualmente se escenifica y se expresa en este ámbito local. Pero también pueden estar reflejando el papel de algunos notables dentro de esas comunidades, sin cuya colaboración resultaba imposible llevar a cabo la recaudación. Cabe suponer -al menos como conjetura- que no fueron meros agentes pasivos sino que pudieron obtener un cierto prestigio local, que se vincularía también a la estrategia de crear ancestros como elementos de identidad de una comunidad. La localización de las pizarras de La Genestosa en torno a una estructura concreta y el hecho de que esta se encuentre muy cercana a la única tumba excavada en la roca, posible vestigio de un enterramiento vinculado a la memoria de los ancestros, podría ser una prueba, endeble eso sí, en ese sentido.

En cualquier caso, este patrón quizá no explique el caso de El Pelícano, donde la principal particularidad proviene de que la pieza recuperada es de texto y no numérica. En cambio, permitiría la interpretación de numerosas pizarras numéricas -las más comunes- en contextos donde no se observa una alta concentración de hallazgos, es decir donde no hay oficinas contables. En definitiva, serían la huella de una estructura de poder que emergió a partir del siglo $\mathrm{V}$, y que se basó en un dominio más bien indirecto de las comunidades rurales, una especie de "poder blando" que, a pesar de ello o quizá gracias a ello, pudo haber sobrevivido hasta comienzos del siglo VIII. No obstante, la escasa concreción cronológica con la que contamos nos obliga a plantear esa posible explicación en término de una hipótesis de trabajo que debe ser analizada.

Fecha de recepción: 2 de agosto de 2014

Fecha de aceptación: 12 de diciembre de 2014

\footnotetext{
79 Sobre el papel de las iglesias, véase Alexandra ChaVArRíaArnau, "Churches and aristocracies in seventhcentury Spain: some thoughts on the debate on Visigothic churches", Early Medieval Europe 18:2 (2010), pp. 160-174.

80 C. Wickham, Framing..., p. 264.

81 Como señala Juan Antonio Quirós CAstillo, “Archaeology of power...”, p. 208, los objetos o prácticas que se pueden identificar con marcadores de jerarquización social dependen en buena medida de su contexto, es decir que no tienen necesariamente ese valor por sí mismos.
} 


\section{ANEXO 1. \\ DESCRIPCIÓN DE LAS PIZARRAS NUMÉRICAS HALLADAS EN LA GENESTOSA (CASILLAS DE FLORES, SALAMANCA)}

\begin{tabular}{|c|c|}
\hline $\mathbf{N}^{0}$ Pizarra & 1 \\
\hline Unidad Estratigráfica & 408 \\
\hline Medidas (en cms) & $10 \times 5,5 \times 10$ \\
\hline Características formales & $\begin{array}{l}\text { La inscripción aparece en una de las caras, pero la } \\
\text { exfoliación de la pieza ha hecho que se perdieran } \\
\text { algunos signos de las partes que podrían haberse } \\
\text { conservado. Las grafías de los números se sitúan } \\
\text { en torno a } 0,8-1 \mathrm{~cm} \text {. Se conservan } 5 \text { fragmentos no } \\
\text { completos de línea separados cada uno de ellos por un } \\
\text { trazo horizontal }\end{array}$ \\
\hline Transcripción & $\begin{array}{l}\text { 1. V } \overline{\mathrm{II}} \mathrm{I} I \\
\text { 2. } \mathrm{I} I \mathrm{I} \\
\text { 3. } \overline{\mathrm{II}} \mathrm{V} \overline{\mathrm{II}} \\
\text { 4. } \overline{\mathrm{II}} \overline{\mathrm{II}} \\
\text { 5. } \overline{\mathrm{II}}\end{array}$ \\
\hline
\end{tabular}

\begin{tabular}{|l|l|}
\hline No Pizarra & 2 \\
\hline Unidad Estratigráfica & 408 \\
\hline Medidas (en cms) & $8,1 \times 4,4 \times 5$ \\
\hline Características formales & $\begin{array}{l}\text { La inscripción de encuentra por una sola de las caras, } \\
\text { aunque la deficiente conservación, producto de la } \\
\text { exfoliación de la pieza, provoca que únicamente se } \\
\text { puedan rastrear 5 líneas muy incompletas. Cada una de } \\
\text { las líneas se encuentra separada por un trazo horizontal, } \\
\text { en forma de renglón, de la siguiente. Las grafías de los } \\
\text { números se sitúan entre 0,8-1 cm. }\end{array}$ \\
\hline Transcripción & $\begin{array}{l}\text { 1.I I } \\
\text { 2. VII } \\
\text { 3. II I II } \\
\text { 4. II I I } \\
\mathbf{5 . I}\end{array}$ \\
\hline
\end{tabular}




\begin{tabular}{|l|l|}
\hline $\mathbf{N}^{0}$ Pizarra & 3 \\
\hline Unidad estratigráfica & 408 \\
\hline Medidas (en cms) & $3,5 \times 2,9 \times 3$ \\
\hline Características formales & $\begin{array}{l}\text { Pequeño fragmento de pizarra inscrita por una sola } \\
\text { cara y con una conservación muy deficiente. Las dos } \\
\text { líneas que pueden todavía verse apenas son unos pocos } \\
\text { signos. Cada una de las líneas está separada por trazos } \\
\text { horizontales en forma de renglones. Las grafías miden } \\
\text { entre } 0.8 \text { y } 1 \text { cm. }\end{array}$ \\
\hline Transcripción & $\begin{array}{l}\mathbf{1 . X} \overline{I I} \text { I } \\
\mathbf{2 .}\end{array}$ \\
\hline
\end{tabular}

\begin{tabular}{|l|l|}
\hline $\mathbf{N}^{\mathbf{0}}$ Pizarra & 4 \\
\hline Unidad estratigráfica & 408 \\
\hline Medidas (en cms) & $3,6 \times 2,7 \times 4$ \\
\hline Características formales & $\begin{array}{l}\text { Pequeño fragmento de una pieza mucho mayor, con } \\
\text { las mismas características formales que el resto. Así, } \\
\text { la inscripción aparece exclusivamente en una de las } \\
\text { caras, que, por otro lado, está bastante deteriorada. } \\
\text { Las grafías miden alrededor de 1 cm y las líneas se } \\
\text { encuentran separadas por trazos horizontales. }\end{array}$ \\
\hline Transcripción & $\begin{array}{l}\mathbf{1 . X} \\
\mathbf{2 . I} \text { II }\end{array}$ \\
\hline
\end{tabular}

\begin{tabular}{|l|l|}
\hline $\mathbf{N}^{0}$ Pizarra & 5 \\
\hline Unidad estratigráfica & 408 \\
\hline Medidas (en cms) & $3,1 \times 1,6 \times 3$ \\
\hline Características formales & $\begin{array}{l}\text { Pequeño fragmento de una pieza mucho mayor con } \\
\text { una conservación muy deficiente. Apenas se observan } \\
\text { algunos trazos sin que puedan observarse con claridad } \\
\text { la presencia de números. No obstante, parece tratarse } \\
\text { de parte de algunas cifras y, al igual que en el resto de } \\
\text { los casos, solo aparece inscrita en una cara. }\end{array}$ \\
\hline Transcripción & $\begin{array}{l}\mathbf{1 .} \\
\mathbf{2 .}\end{array}$ \\
\hline
\end{tabular}




\begin{tabular}{|l|l|}
\hline $\mathbf{N}^{\mathbf{0}}$ Pizarra & 6 \\
\hline Unidad estratigráfica & 410 \\
\hline Medidas (en cms) & $2,9 \times 1,5 \times 3$ \\
\hline Características formales & $\begin{array}{l}\text { Pequeño fragmento de una pieza mucho mayor con } \\
\text { una conservación muy deficiente. Se observan algún } \\
\text { número, así como una línea de separación. Al igual que } \\
\text { en el caso de los fragmentos procedentes de la UE408, } \\
\text { solo aparece inscrita en una cara. De hecho, podría } \\
\text { tratarse de un fragmento procedente de la misma pieza }\end{array}$ \\
\hline Transcripción & $\mathbf{1 . V}$ \\
\hline
\end{tabular}

\begin{tabular}{|l|l|}
\hline $\mathbf{N}^{\mathbf{0}}$ Pizarra & 7 \\
\hline Unidad estratigráfica & 410 \\
\hline Medidas (en cms) & $2,1 \times 2,6 \times 4$ \\
\hline Características formales & $\begin{array}{l}\text { Pequeño fragmento de una pieza mucho mayor con una } \\
\text { conservación muy deficiente. La superficie utilizada } \\
\text { para la inscripción conserva una coloración rojiza, que } \\
\text { no es infrecuente en otros casos documentados. No } \\
\text { obstante, ese rasgo diferencia a este fragmento de otros, } \\
\text { por lo que parece proceder de una pieza diferente. Por } \\
\text { otro lado, apenas se observan algunos trazos sin que } \\
\text { puedan distinguirse los números. Al igual que en el } \\
\text { resto de los casos, solo aparece inscrita en una cara. }\end{array}$ \\
\hline Transcripción & $\begin{array}{l}\text { 1.I II } \\
\mathbf{2 .} \overline{\text { II }} \\
\text { Lectura muy dudosa (faltan partes de las cifras) }\end{array}$ \\
\hline
\end{tabular}

\begin{tabular}{|l|l|}
\hline $\mathbf{N}^{\mathbf{0}}$ Pizarra & 8 \\
\hline Unidad estratigráfica & 410 \\
\hline Medidas (en cms) & 11,3 × 3,6 x 2 \\
\hline Características formales & $\begin{array}{l}\text { Se trata de un fragmento de una pizarra de mayor } \\
\text { tamaño, concretamente sería parte del extremo derecho } \\
\text { de la zona de inscripción. El fragmento presenta una } \\
\text { coloración rojiza en la zona de escritura, así como un } \\
\text { considerable grosor }(2 \mathrm{cms}) \text {. Por otra parte, se observa } \\
\text { el inicio de 4 líneas, con números cuyas grafías son de } \\
\text { mayor tamaño (aprox. } 2 \text { cms) y el trazo es descuidado. } \\
\text { Una prueba de ese menor detalle en la inscripción es } \\
\text { la ausencia de líneas separadoras. Todo ello permite } \\
\text { afirmar que este fragmento corresponde a otra pizarra } \\
\text { con inscripción numérica, quizá la misma a la que } \\
\text { pertenece UE410/2, aunque no es seguro. Al igual que } \\
\text { en el resto de los casos, solo aparece inscrita en una cara. }\end{array}$ \\
\hline
\end{tabular}




\begin{tabular}{|l|l|}
\hline Transcripción & $1 . \mathrm{X}$ \\
& $2 . \mathrm{X}$ \\
& 3.X \\
& 4. I V \\
\hline
\end{tabular}

